\title{
Numerical investigation of continuous, high density turbidity currents response, in the variation of fundamental flow controlling parameter
}

\author{
Anastasios N. Georgoulas ${ }^{1}$, Kyriakos I. Kopasakis ${ }^{1}$, Panagiotis B. Angelidis ${ }^{1}$, \\ Nikolaos E. Kotsovinos ${ }^{1}$, \\ ${ }^{1}$ Laboratory of Hydraulics and Hydraulic Structures
}

Democritus University of Thrace, Department of Civil Engineering, V. Sofias 12

GR-67 100 Xanthi, Greece

Tel: +302541079321, FAX: +302541079604

ageorg@civil.duth.gr

\section{Abstract}

During floods, the density of river water usually increases due to the increase in the concentration of the suspended sediment that the river carries, causing the river to plunge underneath the free surface of a receiving water basin and form a turbidity current that continues to flow along the bottom. The study and understanding of such complex and rare phenomena is of great importance, as they constitute one of the major mechanisms for suspended sediment transport from rivers into the ocean, lakes or reservoirs. In the present paper a previously tested and verified numerical model [1] is applied in laboratory scale numerical experiments of continuous, high density turbidity currents. The turbidity currents are produced by the steady discharge of fresh water - suspended sediment mixtures, into an inclined channel which is connected at its downstream end to a wide horizontal tank. Both, channel and tank are initially filled with fresh water. This configuration serves as a simplified experimental analog of natural, hyperpycnal turbidity currents that are formed at river outflows in the sea, lakes or reservoirs and usually travel within subaqueous canyon-fan complexes. The main aim is to investigate the exact qualitative and quantitative effect of fundamental, flow controlling parameters in the hydrodynamic and depositional characteristics of continuous, high density turbidity currents. According to the authors' best knowledge, the present paper constitutes the first attempt in the literature, where the isolated effects of each individual controlling parameter as well as their relative importance on the hydrodynamic characteristics of continuous, high-density turbidity currents are quantitatively evaluated in detail. The numerical model used, is based on a multiphase modification of the Reynolds Averaged Navier-Stokes equations (RANS). For turbulence closure the Renormalizationgroup (RNG) $\mathrm{k}-\varepsilon$ model is applied, which is an enhanced version of the widely used standard $\mathrm{k}-\varepsilon$ model.

Keywords: Turbidity currents, hyperpycnal flows, CFD numerical modelling, suspended sediment transport, multiphase flows 


\section{Introduction}

In nature, there is a large class of flows that are generated and driven by the density difference between two or even more fluids. These flows are known as gravity or density currents. Despite the fact that the density difference between two fluids usually arises due to differences in temperature or salinity, it can also arise due to the presence of suspended solid particles. These particulate currents, in the case of sediment laden water that enters a water basin, are classified according to the density difference with the ambient fluid, into three major categories: (a) hypopycnal currents, when the density of the sediment laden water is lower than that of the receiving water basin, (b) homopycnal currents, when the density of the sediment laden water is almost equal to that of the receiving water basin, and (c) hyperpycnal currents when their density is much greater than that of the receiving water body [2]. In the case of floods, the suspended sediment concentration of river water rises to a great extent. Hence, the river plunges to the bottom of the receiving basin and forms a hyperpycnal plume which is also known as turbidity current. Such flows are usually formed at river exits in oceans, lakes or reservoirs, and can travel remarkable distances transferring, eroding and depositing large amounts of suspended sediments [2].

Turbidity currents are very difficult to be observed and studied in the field. This is due to their rare and unexpected occurrence nature, as they are usually formed during floods. Therefore, field investigations are usually limited to the study of the deposits originating from such currents [3]. However, the last decades, considerable research on the morphology of turbiditic systems and general deep-marine depositions is being increasingly done with the use of 3D seismic sections [4]. On the other hand, scaled laboratory experiments constitute an alternative and widely used method for simulating and studying the dynamics of turbidity currents. Many researchers have been focused in the study of the flow dynamics, depositional and erosional characteristics of laboratory turbidity currents, using scaled experimental models [58]. Advances in experimental technology in the last decades have increased the existing knowledge from macroscopic and qualitative descriptions of turbidity current behaviour and deposits, to detailed, quantitative results relating to the actual flow characteristics, such as the velocity, concentration as well as the turbulence structure 
of such flows [9-13].

Mathematical and numerical models when properly designed and tested against field or laboratory data, can provide significant knowledge for the hydrodynamics of density driven flows such as density currents and particle-laden flows such as turbidity currents. Up to present, there are various numerical investigations dealing with such flows, providing valuable results [14-33]. However most of these previous works treat turbidity currents with a quasi-single-phase approach, solving one set of continuity and momentum equations for the ambient fluid and treating the transport of sediment particles through an advection-diffusion equation for sediment concentration. According to the authors' best knowledge, the first numerical effort that treats turbidity current flows through a multi-phase approach, assuming that the sediment-laden turbidity current flow consists of separate solid and fluid phases, is the recent work by Georgoulas et al. (2010) [1]. In the proposed work a separate velocity field is calculated for each phase (water and sediment classes), since the laws for the conservation of mass and momentum are modified accordingly in order to be satisfied by each phase individually. In more detail, a 3D numerical model that simulates the dynamics and flow structure of turbidity currents, through a multiphase flow approach is proposed, using the commercial CFD code FLUENT. A series of numerical simulations that reproduce particular published laboratory flows are presented. The detailed qualitative and quantitative comparison of numerical with laboratory results indicates that apart from the global flow structure, the proposed numerical approach efficiently predicts various important aspects of turbidity current flows, such as the effect of suspended sediment mixture composition in the temporal and spatial evolution of the simulated currents, the interaction of turbidity currents with loose sediment bottom layers and the formation of internal hydraulic jumps.

In the present paper, the multiphase numerical approach that is validated in the work of Georgoulas et al. (2010) [1], is further applied in order to investigate the exact qualitative and quantitative effect of fundamental flow controlling parameters, such as bed slope and roughness, initial suspended sediment concentration and diameter, in the hydrodynamic and depositional characteristics of continuous, high density turbidity currents. For this purpose, four different series of parametric numerical experiments are conducted, using a laboratory scale experimental set-up, similar to the one used in the laboratory experiments of Baas et al. (2004) [12]. In 
each series of numerical experiments, the initial value of only one of the above mentioned controlling parameters (bed slope, initial suspended sediment concentration, suspended sediment diameter and bed roughness) is varied, while the initial values of the rest parameters are kept constant.

\section{Numerical Model Description}

\subsection{Overview}

Turbidity current flows can be characterized as multiphase flow systems, since they consist of a primary fluid phase (water) and secondary granular phases (suspended sediment classes) dispersed into the primary phase. Therefore, turbidity currents can be modeled through the application of suitable multiphase numerical models. The commercial CFD code ANSYS FLUENT that is adopted for the simulations of the present paper, provides various multiphase models [34]. The "Eulerian" model that has been chosen for the simulations of the present paper may require more computational effort, but it can handle a wider range of particulate loading values and is more accurate than the other available multiphase models in FLUENT. In this multiphase model, the different phases are treated mathematically as interpenetrating continua and therefore the concept of phasic volume fraction is introduced, where the volume fraction of each phase is assumed to be a continuous function of space and time. The sum of the volume fractions of the various phases is equal to unity. An accordingly modified set of momentum and continuity equations for each phase is solved. Pressure and inter-phase exchange coefficients are used in order to achieve coupling for these equations. The coupling of granular (fluid-solid) flows is handled differently than in the case of non-granular (fluid-fluid) flows. For granular flows, the properties are obtained from application of the kinetic theory. The type of phases involved, also defines the momentum exchange between the various phases. A more detailed overview of the application of the "Eulerian" multiphase model to the numerical simulation of turbidity currents can be found in the work of Georgoulas et al. (2010) [1].

The motion of the suspended sediment particles within a turbidity current as well as the motion generated in the ambient fluid are of highly turbulent nature. In 
order to account for the effect of turbulence in the numerical simulations of the present investigation, a RANS (Reynolds-averaged Navier-Stokes equations) approach is applied. The Renormalization-group (RNG) k- $\varepsilon$ model is applied for turbulence closure, modified accordingly in order to simultaneously account for the primary (continuous) phase and the secondary (dispersed) phases of the simulated flows [34]. A more detailed overview of the RNG k- $\varepsilon$ turbulence model as well as of the proposed multi-phase modification can be found in the work of Georgoulas et al. (2010) [1].

\subsection{Governing Equations}

The volume of phase $q, \mathrm{~V}_{\mathrm{q}}$ is defined by the following relationship [1]:

$$
\mathrm{V}_{\mathrm{q}}=\underset{\mathrm{V}}{\mathrm{U} a}{ }_{\mathrm{q}} \mathrm{dV}
$$

where,

$$
\underset{\mathrm{q}=1}{\mathrm{n}} \mathrm{a}_{\mathrm{q}}=1
$$

and $\alpha_{\mathrm{q}}$ is the volume fraction of phase $\mathrm{q}$.

The effective density of phase $q$ is:

$$
\stackrel{\ddot{Y}}{r_{q}}=a_{q} r_{q}
$$

where $\rho_{\mathrm{q}}$ is the physical density of phase $q$.

The continuity, the fluid-fluid, and fluid-solid momentum equations that are actually solved by the model are described by equations (4), (5) and (6) respectively, for the general case of a n-phase flow consisting of granular and non-granular secondary phases $[1]$ :

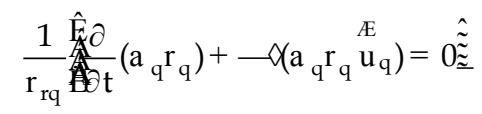

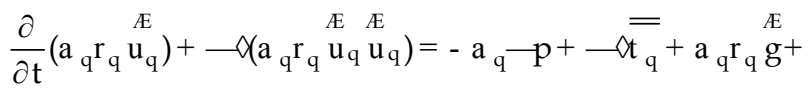

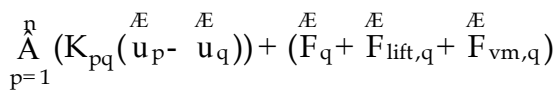

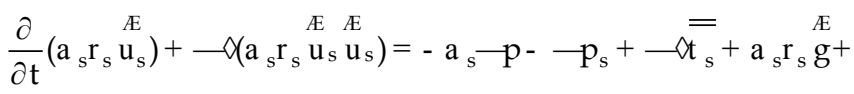

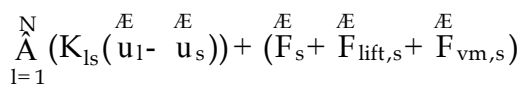

where $\rho_{\mathrm{rq}}$ is the phase reference density, or the volume averaged density of the 
$\mathrm{q}^{\text {th }}$ phase in the solution domain, $\stackrel{\mathbb{E}}{\mathrm{u}_{\mathrm{q}}}$ is the velocity of phase $\mathrm{q}, \stackrel{\mathbb{E}}{\mathrm{u}_{\mathrm{p}}}$ is the velocity of phase $\mathrm{p}, p$ is the pressure shared by all phases, $\stackrel{\bar{t}}{\mathrm{q}}_{\mathrm{q}}$ is the $\mathrm{q}^{\text {th }}$ phase stress-strain tensor, $\mathrm{g}$ is the gravitational acceleration, $\mathrm{K}_{\mathrm{pq}}$ is the interphase momentum exchange

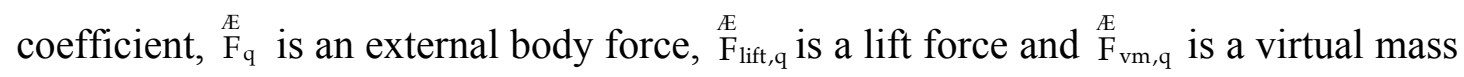
force. $\mathrm{K}_{\mathrm{ls}}=\mathrm{K}_{\mathrm{sl}}$ is the momentum exchange coefficient between fluid phase $l$ and solid phase $s$ and $N$ is the total number of phases.

The general transport equations for the turbulence kinetic energy $k$ and the turbulence dissipation rate $\varepsilon$, of the RNG k- $\varepsilon$ turbulence model, can be described by equations (7) and (8) respectively [1]:

$$
\begin{aligned}
& \frac{\partial}{\partial \mathrm{t}}(\mathrm{rk})+\frac{\partial}{\partial \mathrm{x}_{\mathrm{i}}}\left(\mathrm{rku}_{\mathrm{i}}\right)=\frac{\partial}{\partial \mathrm{x}_{\mathrm{j}}} \mathrm{k}_{\mathrm{eff}} \frac{\partial \mathrm{k}}{\partial \mathrm{x}_{\mathrm{j}}} \frac{\hat{\tilde{\tilde{z}}}}{\tilde{z}^{2}} \mathrm{G}_{\mathrm{k}}+\mathrm{G}_{\mathrm{b}}-\mathrm{re} \\
& \frac{\partial}{\partial t}(\mathrm{re})+\frac{\partial}{\partial \mathrm{x}_{\mathrm{i}}}\left(\mathrm{reu}_{\mathrm{i}}\right)=\frac{\partial}{\partial \mathrm{x}_{\mathrm{j}}} \mathrm{e}_{\mathrm{eff}} \frac{\partial \mathrm{e} \hat{\tilde{\tilde{z}}}}{\partial \mathrm{x}_{\mathrm{j}}}+ \\
& C_{1 e} \frac{e}{k}\left(G_{k}+C_{3 e} G_{b}\right)-C_{2 e} \frac{e^{2}}{k}-R_{e}
\end{aligned}
$$

where $u$ represents velocity, $\rho$ is the local mixture density, $G_{k}$ is the generation of turbulence kinetic energy due to mean velocity gradients, $G_{b}$ is the generation of turbulence kinetic energy due to buoyancy, $\alpha_{k}$ and $\alpha_{\varepsilon}$ are the inverse effective Prandtl numbers for $k$ and $\varepsilon$ respectively, $\mu_{\text {eff }}$ is the effective viscosity and $C_{1 \varepsilon}, C_{2 \varepsilon}$ and $C_{3 \varepsilon}$ are turbulence model constants. The term $R_{\varepsilon}$ in the $\varepsilon$ equation accounts for the effects of rapid strain and streamline curvature.

Further details regarding the governing equations as well as the calculation and importance of their various terms, for the simulation of turbidity current flows can be found in the work of Georgoulas et al. (2010) [1].

\subsection{Boundary Conditions}

For all the numerical simulations that are presented in the present paper, at the inlets, a velocity-inlet boundary condition is used. For the outlets, a pressure-outlet boundary condition is applied. At the free ambient water surfaces, a symmetry boundary condition is used. Finally, the solid boundaries of the computational domains are specified as stationary walls with a no-slip shear condition. Further details regarding these types of boundary conditions can be found in the work of Georgoulas et al. (2010) [1]. 


\subsection{Solution Procedure and Numerical Model Set-up}

The governing equations in the proposed multiphase numerical approach are solved sequentially, using the control-volume method. Hence, the equations are integrated about each control-volume, yielding discrete equations for the conservation of each quantity. An implicit formulation is used, in order for the discretized equations to be converted to linear equations for the dependent variables in every computational cell.

The main set-up parameters and characteristics of the optimum (validated) version of the proposed numerical model in ANSYS FLUENT, regarding the simulations presented in the present paper are summarized in Table 1. Further details regarding the solution procedure and the model set-up can be found at ANSYS FLUENT Theory and User's guide [34].

\section{Numerical Model Validation}

The detailed verification of the proposed numerical model has been previously conducted in the work of Georgoulas et al. (2010) [1], where two different series of published laboratory experiments on turbidity currents, conducted by Gladstone et al. (1998) [11] and Baas et al. (2004) [12] are reproduced numerically, and the results are compared aiming to evaluate how realistic and reliable the numerical simulations of the proposed model are. The first series of laboratory experiments [11] consist of fixed-volume, lock-gate releases of dilute mixtures containing two different sizes of suspended silicon carbide particles, in various initial proportions, within a rectangular flume (Run A - Run G). The second series of laboratory experiments [12] consist of high-density sediment-water mixtures released with a steady rate, through a small inflow gate, into an inclined channel which is connected to a tank, were an expansion table covered with loose sediment is positioned. The mixtures consist of either fine sand, very fine sand or coarse silt. Apart from the suspended sediment grain size, the initial suspended sediment volume fraction, the water-sediment mixture discharge and the channel slope angle and bed roughness, are varied among these experimental runs (Run 1 - Run 14).

Details regarding the above mentioned laboratory experiments (experimental set-up, initial conditions) and their numerical reproduction (computational geometry, 
computational mesh, boundary conditions, etc.) can be found in the work of Georgoulas et al. (2010) [1]. However, for the purposes of the present paper, the key quantitative results that prove that the proposed numerical model predictions are realistic and reliable are presented and discussed in subsections 3.1 and 3.2 that follow, for the cases of the fixed-volume releases [11] and the steady-state releases [12], respectively.

\subsection{Fixed-Volume Releases}

Front speed is one of the most studied parameters for lock-exchange turbidity currents. Figure 1 compares the simulated [1] and observed [11] current front position versus time for all the lock-gate cases considered in the work of Georgoulas et al. (2010) [1]. As it can be seen, in general the numerical simulations show a good match with the experimental data, adequately predicting the differences in the flow front advance among the generated currents with respect to the different relative proportions of coarse $(\% \mathrm{C}$ in the figure legend) and fine particles $(\% \mathrm{~F}$ in the figure legend) that were used in the initial suspensions. The observed divergence between the experimental and the numerical curves at various flow times, might be partially attributed to possible over-estimation or under-estimation of the flow front position in the particular laboratory runs, due to the difficulty in the visual definition of the exact flow front position, since these laboratory difficulties are stated in the work of Gladstone et al. (1998) [11]. Another possible reason for the observed divergence might be the overall assumptions in the numerical simulations (e.g. uniform grain size in each particle class).

In order to also examine the validity of the vertical structure of the simulated lock-gate cases, the non-dimensional vertical profiles of the streamwise velocity component for numerical runs $\mathrm{A}$ and $\mathrm{D}$ are constructed and compared with analogous dimensionless experimental data from the laboratory work of Garcia (1994) [9]. The numerical profiles and the corresponding experimental data are compared in Figure 2. As it can be seen, the numerically predicted dimensionless profiles [1] fall within the general scatter range of the dimensionless data for subcritical currents that resulted from the laboratory experiments [9]. Therefore, it can be concluded that the proposed numerical model gives fairly reasonable predictions regarding the vertical structure of the simulated currents. 


\subsection{Steady-State Releases}

The relationship between head velocity and initial suspended sediment concentration for fine-sand, very-fine sand and coarse-silt laden turbidity currents is depicted in Figure 3, both for the numerical [1] and the corresponding experimental runs (Runs 1, 3, 4, 7, 8, 13 and 14) [12]. Once again, the numerical values are very close to the corresponding experimental values. Moreover, it is evident that the numerical model captures the same trend in the head velocity variation with respect to the increase of the initial suspended sediment concentration, in comply with the experimental runs.

In order to examine the validity of the vertical structure of the simulated steady-state releases, the non-dimensional vertical profiles of the streamwise velocity component for numerical runs 1,7 and 14 from the work of Georgoulas et al. (2010) [1] are constructed and compared with corresponding dimensionless experimental data from the laboratory work of Garcia (1994) [9]. The numerical profiles and the corresponding experimental data are illustrated in Figure 4. As it can be seen, the numerically predicted dimensionless data [1] fall within the scatter range of the dimensionless data for supercritical currents that resulted from the laboratory experiments [9]. However, at the near-wall region of the numerical profiles, a sharp change is observed in relation to the experimental values. This sharp change at the near-wall region could be attributed to the $3 \mathrm{~cm}$ mesh resolution that was used in the steady-state release runs and the application of the "standard wall functions" that do not resolve but instead link the viscosity affected near-wall region with the fully turbulent outer region, though the use of empirically derived formulas. Since, this sharp change is not presented in the lock-gate cases (Figure 2), it can be concluded that the application of the "enhanced wall treatment" that was used in the numerical reproduction of lock-gate releases should be preferable at the bottom wall boundaries, in cases that the complexity and size of the computational domain geometry as well as the available computational resources, allow the construction of high-resolution meshes at the near-wall regions, since this provides more accurate and detailed predictions in the vicinity of the bottom wall boundaries. 


\section{Application of Numerical Model}

The geometry and the general conditions of the physical problem that is investigated in the present paper are depicted in Figure 5. As it can be seen, the physical problem consists of turbidity currents that are generated during the continuous inflow of fresh water - suspended sediment mixtures (through an inflow gate, of height $h_{\text {gate }}=0.035 \mathrm{~m}$, width $w_{\text {gate }}=0.18 \mathrm{~m}$ and cross-sectional area of $A_{\text {gate }}=0.0063 \mathrm{~m}^{2}$ ), into an inclined channel connected to a horizontal bottomed tank at its downstream end. The turbidity current flow within the inclined channel is laterally confined (confined turbidity current), while after its exit from the inclined channel the turbidity current is free to expand in all directions (unconfined turbidity current). The proposed laboratory scale configuration, serves as a simplified experimental analog of natural, hyperpycnal turbidity currents. This type of currents are usually formed at river outflows and initially travel, laterally confined within a subaqueous canyon with a sloped bottom (inclined channel) and then, after they exit from the downstream end of the canyon, they spread out laterally unconfined in the horizontal or mild sloped bottom (tank) of the receiving basin (sea, lake or reservoir) where they gradually lose their strength and deposit the initially suspended sediment particles, forming fanshaped deposits.

The flows examined in the present paper, are treated numerically as multiphase flows, where fresh water constitutes the primary continuous phase and suspended sediment particles constitute the secondary phase. As mentioned previously, the numerical model used in the simulations is based on a multiphase modification of the Reynolds Averaged Navier-Stokes equations (RANS). For turbulence closure the Renormalization-group (RNG) $\mathrm{k}-\varepsilon$ model is applied, which is an enhanced version of the widely used, standard $\mathrm{k}-\varepsilon$ model. The proposed multiphase numerical approach for the simulation of turbidity current flows, is described in detail, tested and verified against available laboratory experiments from the literature, in the work of Georgoulas et al. (2010) [1].

The symbols and the explanations of the controlling flow parameters that are investigated (varied) in each series of numerical experiments, in the present paper, are summarized in Table 2. Each series of numerical experiments consists of four runs. The initial conditions of these runs are summarized in Table 3. The numerical 
experiments in each case are named accordingly to the varied parameter and its corresponding value in each numerical experiment. It should also be mentioned that in each series of numerical experiments (A, B, C and D) there is a common Reference Numerical Experiment (R.N.E.) (channel slope $S=5$, suspended sediment concentration $C=25 \%$ by vol., grain diameter $D=150 \mu m$, smooth bed with sand equivalent roughness of $R=0 \mu \mathrm{m}$ ), which for ease purposes in the analysis of the results is named as S5, C25, D150 and R0 for Series A, B, C and D, respectively. Finally, it should be mentioned that the inflow discharge of the incoming fresh water - suspended sediment mixtures is continuous and steady, with a value of $Q_{\text {inflow }}=0.0078 \mathrm{~m}^{3} / \mathrm{sec}$ (that corresponds in an inflow velocity value of $\left.U_{\text {inflow }}=1.24 \mathrm{~m} / \mathrm{sec}\right)$ in all series of numerical experiments.

As it can be seen from Table 3, the overall channel slope values that were used in the numerical experiments of the present investigation are $1,5,10$ and 20 . Therefore, in order to conduct the numerical experiments of Series A, four different geometries, one for each channel slope, where constructed. In all the rest series of numerical experiments $(\mathrm{B}, \mathrm{C}$ and $\mathrm{D})$ the geometry with $5^{\circ}$ channel slope is used. The computational geometry, computational mesh and boundary conditions, that were used in the numerical simulations are illustrated in Figure 6 , for the case of the $5^{\circ}$ channel slope that also corresponds to the R.N.E.. For the rest configurations (channel slopes 1, 10 and 20) these characteristics are similar and therefore are not illustrated schematically.

In the numerical geometries, that correspond to a channel slope of $1,5,10$ and 20 , the computational meshes consist of a total number of cells (control volumes) of 51770, 58398, 69370 and 93487, respectively. In all situations the same mesh characteristics (cell size, cell clustering growth rates, cell layers in the vicinity of the bottom boundary etc.) are used. As it can be seen from Figure 6, the largest part of the computational mesh consists of tetrahedral cells of varying size, that are locally refined at regions where more computational accuracy is required (regions of sudden changes in the calculated quantities), such as the region in the vicinity of the inflow boundary and the downstream end of the inclined channel.

In order to apply the "enhanced wall treatment" for the calculation of the turbulent quantities in the vicinity of the bottom wall boundary (see Subsection 3.2 ), 
five parallel layers of prismatic cells where used, the height of which is progressively increased with the vertical distance from the bottom boundary (Figure 6). The proposed treatment has been proven to give more accurate results than the "standard wall functions" approach which is another widely used near wall treatment method. Details regarding these treatments can also be found in the paper by Georgoulas et al. (2010) [1] and therefore are not discussed in the present paper.

In order to ensure that the numerical solutions presented here are mesh independent, sensitivity tests were performed with computational meshes of different total cell number. Figure 7 illustrates the flow front position of the generated turbidity current with respect to time, for three different computational meshes in the case of the R.N.E.. The first computational mesh is the one used in the simulations of the present paper (58398 computational cells), the second one is a coarser mesh (36133 computational cells) and the third one is a finer mesh (119907 computational cells). It is obvious (Figure 7) that the resulting curves in each case show a good degree of convergence and therefore the solution can be considered to be mesh independent. In more detail, comparing the results of the coarser mesh with the corresponding results of the finer mesh, it is concluded that increasing the total number of cells by a factor of 3.33, the average difference of the flow front advance values with respect to time, is only $1.85 \%$.

\section{Results and Discussion}

In order to visualize and understand the geometric and transient characteristics of the generated turbidity current flows, in the numerical simulations of the present paper, the first subsection of the results (Subsection 5.1) presents some indicative qualitative results that illustrate the time evolution of the turbidity current that is formed in the case of the R.N.E. The next subsections of the results (subsections 5.2, 5.3 and 5.4) quantify the effect of the variation of each one of the varied controlling parameters, in fundamental hydrodynamic and depositional characteristics of the generated turbidity currents. The examined characteristics are the flow front advance with respect to time as well as the main expansion angle of the turbidity currents within the expansion tank and the volumetric concentration of the suspended sediment particles at the bottom boundary, after their flow has reached a quasi-steady state. 
Finally, in the last subsection (Subsection 5.5) a comparison of the relative percentage effect of the investigated flow controlling parameters, in fundamental flow characteristics, is conducted.

\subsection{Turbidity current flow visualization}

Figure 8 illustrates the three-dimensional time evolution of the interface, between the generated turbidity current and the ambient water, for the case of the R.N.E.. The corresponding time evolution of the fresh water - suspended sediment particles mixture density structure within the generated turbidity current, in a vertical ZX section plane, in the middle of the computational domain $(Y=0 m)$, is depicted in Figure 9. The values of the density contours are determined by the color scale of the legend. It should be noted that in the proposed figure the $\mathrm{Z}$-axis scale has been enlarged for illustration purposes.

From these figures (Figures 8 and 9) it is obvious that $3 \mathrm{sec}$ after the inflow of the fresh water - suspended sediment mixture the generated turbidity current, flows within the inclined channel (laterally confined part of the flow). At $t=5 \mathrm{sec}$, the turbidity current head has already exited from the downstream part of the channel and has started to expand radically in the horizontal bed of the tank (unconfined part of the flow). At $t=10 \mathrm{sec}$ the head of the current has just reached the downstream open boundary of the computational domain, while at $t=20 \mathrm{sec}$ it has already exited the computational domain, from the downstream as well as the left and right side open boundaries. From Figure 9, it is evident that at each of the illustrated flow times, two distinct density layers are formed. The first one is a dense layer with density values ranging approximately from $1200 \mathrm{kgr} / \mathrm{m}^{3}$ to $1600 \mathrm{kgr} / \mathrm{m}^{3}$, which is positioned at the bottom of the turbidity current parallel to the bottom boundary of the computational domain. The second one is a more dilute layer that lies on top of the dense layer, with density values ranging from approximately $1000 \mathrm{kgr} / \mathrm{m}^{3}$ to $1200 \mathrm{kgr} / \mathrm{m}^{3}$. At the top of this dilute layer, the observed fluctuations $\left(1000 \mathrm{kgr} / \mathrm{m}^{3}\right.$ density contour line) are probably due to the considerable mixing of the fresh water - suspended sediment mixture with the ambient fresh water of the computational domain. These observations are in direct quantitative agreement with analogous observations of previous experimental as well as numerical investigations [12, 13, 23]. Finally, it is characteristic that just after the exit of the flow front from the open boundaries of the computational domain $(t=20 \mathrm{sec})$, the vertical density structure of the generated 
turbidity current remains almost steady, with negligible variations (Figure 8, times $t=20 \mathrm{sec}$ and $t=40 \mathrm{sec}$ ). This fact indicates that at flow time $t=40 \mathrm{sec}$ the turbidity current flow within the computational domain has already reached a quasi-steady state.

\subsection{Flow front advance}

Flow front advance with respect to time constitutes one of the most important and widely studied parameter, in the case of gravity (saline density currents) and turbidity currents. In Figure 10 the resulting curves of the generated turbidity current flow front position with respect to time, are illustrated in dimensionless form, for the numerical experiments of Series A (Figure 10a), B (Figure 10b) , C (Figure 10c) and D (Figure 10d) respectively. For comparison purposes, the varied parameter in each series of numerical experiments is normalized with its lowest value $\left(S_{1}=1\right.$ for Series $\mathrm{A}, C_{5}=5 \%$ by vol. for Series B, $D_{80}=80 \mu m$ for Series $\mathrm{C}$ and $R_{80}=80 \mu m$ for Series D), the horizontal distance $X$ of the flow front from the inflow gate is normalized with the width of the inclined channel $(b=0.22 \mathrm{~m})$ and the flow time $t$ is normalized with the time needed for the slowest of the generated turbidity currents (in each series of numerical experiments) to exit from the downstream boundary of the expansion tank $\left(t_{\text {exit }(S 1)}=12 \mathrm{sec}\right.$ for Series A, $t_{\text {exit }(C 5)}=18 \mathrm{sec}$ for Series B, $t_{\text {exit }(D 80)}=10 \mathrm{sec}$ for Series C and $t_{\text {exit }(R 500)}=13 \mathrm{sec}$ for Series D).

As it can be seen from Figure 10, the resulting curves in each numerical experiment of Series A, B, C and D have a similar form, consisting of three distinct parts. In the first part the flow front velocity of the generated turbidity currents is almost steady, in the second part a gradual acceleration of the flow front is observed and in the third part, a gradual deceleration of the flow front is evident. In the first part, the flow of the generated turbidity currents is primarily controlled by their initial momentum, due to the continuous and steady discharge of the inflowing fresh water suspended sediment mixtures (from the inflow gate) and therefore the flow front velocity remains constant. In the second part that the flow front of the currents has already traveled almost half the length of the inclined channel, the observed acceleration of the front is due to the continuous increase of the gravitational force effect, since the currents are flowing over an inclined bottom boundary. Previous investigations on gravity currents (saline density currents) travelling down an inclined 
surface $[7,35,36]$ state that the head of currents travels at a constant speed for slopes $\theta \geq 5^{\circ}$. According to Figure 10, of the present paper, this statement does not hold for high-density turbidity currents, since in all series of numerical experiments (slopes $1^{\circ}$ $\leq \theta \leq 5^{\circ}$ ) the turbidity current head encounters an acceleration stage while travelling within the inclined channel of the computational domain (part 2 in the resulting flow front position - time curves of Figure 10). At the third part, the turbidity currents have already entered the expansion tank and their flow is laterally unconfined, expanding radically in all directions over the horizontal bottom boundary of the tank. Therefore, the continuous reduction of their excess density, due to the continuous entrainment of the ambient water of the tank and the consequent gradual deposition of suspended sediment particles, causes a gradual dissipation and deceleration of the generated turbidity current flows. This deceleration stage of the flow front advance with respect to time is in direct agreement with previous works in density currents travelling over inclined surfaces of very mild slopes $\left(\theta \leq 0.5^{\circ}\right)$ or over a flat, horizontal surface $(\theta=0$ $\left.{ }^{\circ}\right)[7]$.

Comparing the curves of Figure 10a it is concluded that in general, the increase of the channel slope causes a subsequent increase in the traveled distance of the front with respect to time, which becomes gradually considerable after the first (constant velocity) part of the curves. The general increase in the flow front velocity in relation to the increase of the channel bed slope is due to the corresponding increase of the gravitational force component in the direction of the flow, as the generated turbidity currents travel within the inclined channel. Previous investigations on gravity currents $[7,36]$ state that the speed of descent remains roughly constant when the bed slope angle is varied. From Figure 10a, of the present paper, it is obvious that for the case of high-density turbidity currents this is true, only for the initial stage of their flow (part 1 of the resulting curves in Figure 10a) since in a later stage (part 2 of the resulting curves in Figure 10a) the flow front advance velocity increases considerably with the corresponding increase of the channel slope.

Comparing the resulting curves in Figure $10 \mathrm{~b}$ it can be concluded that in general, the increase in the initial value of the suspended sediment volumetric concentration causes a subsequent increase in the traveled distance of the front with respect to time. However, in this case the corresponding increase becomes gradually considerable from the first (constant front velocity) part of the resulting curves, in contradiction to the case of Figure 10a (Series A numerical experiments). The 
increase in the traveled distance of the front with respect to time, in relation to the increase of the initial suspended sediment volumetric concentration, is obviously due to the corresponding increase of the density difference of the generated turbidity current from the ambient water (excess density), which constitutes the main driving force of turbidity current flows. These findings are in direct agreement with previous laboratory experiments on turbidity currents [12] and in indirect agreement with analogous laboratory experiments on saline density currents [36], were the excess density of the gravity current with the ambient fluid is due salinity differences.

Comparing the resulting curves of Figure $10 \mathrm{c}$, it can be concluded that the relatively small increase in the suspended sediment grain diameter, causes a noticeable increase in the flow front traveled distance with respect to time, which as in the case of Series A numerical experiments, starts gradually to become considerable after the first (constant velocity) part of the resulting curves. This has also been observed in previous works on experimental high-density turbidity currents of steady state release type [12]. The increase in the distance traveled by the front with respect to time, in relation to the corresponding increase in the suspended sediment grain diameter, is due to the gradual increase of the gravitational force effect (as the turbidity currents travel within the inclined channel) as the component of the suspended sediment settling velocity, in the direction of the flow, also increases. This finding is in contradiction with previous investigations on fixed-volume turbidity current experiments (lock-gate releases) [11], where the increase of the suspended sediment grain size in the initial suspension reduces the flow front advance velocity. This seems more reasonable, since large particles settle down more quickly than small particles, leading to a more rapid loss of the excess density of the generated current. However, in the cases considered in the present paper the resulting difference is due to the continuous inflow of the fresh water - suspended sediment mixtures from the inflow gate (steady state releases).

Finally, from Figure 10d it is obvious that in general, the increase of the bed roughness causes a small reduction in the distance traveled by the front with respect to time which starts to become considerable after the entrance of the generated turbidity currents in the expansion tank. Therefore, it can be concluded that the bed roughness may affect turbidity current advancing velocities, only in cases of very mild slopes. The general reduction in the flow front velocity of the generated currents with the corresponding increase of the bed roughness is due to the gradual increase of the 
friction force between the bottom boundary and the expanding turbidity current, in agreement with previous macroscopic laboratory observations [12].

\subsection{Expansion angle}

According to the authors' best knowledge most of the previous investigations on the dynamic characteristics of turbidity currents deal with laterally-constrained flows. Therefore, the expansion angle of a turbidity current that expands unconstrained in all directions has not been studied previously. The dependence of the expansion angle of the generated turbidity currents as well as the densimetric Froude number at the downstream end of the channel, from the varied parameter in each series of the present numerical experiments (A, B, C and D) is illustrated in Figure 11 , at flow time $t=40 \mathrm{sec}$ that the generated turbidity current in each case, has reached a quasi-steady state. As it can be seen, the expansion angle decreases as the channel slope increases, while the densimetric Froude number increases (Figure 11a). The increase of the inflow mixture suspended sediment concentration causes an increase in the expansion angle and a decrease in the densimetric Froude number (Figure 11b). The increase of the suspended sediment grain diameter causes a decrease in the expansion angle with a gradually reducing rate and an initial increase in the densimetric Froude number followed by a more rapid decrease (Figure 11c). Finally, the increase of the bottom boundary roughness causes an increase in the main expansion angle and a general decrease in the densimetric Froude number (Figure 11d). Therefore it can be concluded that the main expansion angle seems to be inversely related, in a way, to the densimetric Froude number at the downstream end of the inclined channel.

In order to quantify the proposed relation in the diagram of Figure 12, the main expansion angle of the generated turbidity currents, within the expansion tank, is plotted against the densimetric Froude number, at the exit point of the inclined channel for all of the conducted numerical experiments (Series A, B, C and D), at flow time $t=40 \mathrm{sec}$, where the flow of the generated turbidity currents has reached a quasi-steady state. As it can be seen, the main expansion angle of the generated turbidity current decreases exponentially with the increase of the densimetric Froude number. 


\subsection{Bottom boundary suspended sediment volumetric concentration}

Most previous investigations on turbidity current deposits usually focus on the deposit density with respect to the distance from the origin, long after the passage of the turbidity current that the suspended sediment particles have fully settled, on the bottom boundary of the experimental tank or the computational domain $[11,12,14]$. According to the authors' best knowledge, there are not any previous investigations dealing with the bottom suspended sediment concentration response in the variation of turbidity current flow controlling parameters, while the turbidity current event is still in progress. Therefore, in the present section of the paper, the response of the suspended sediment volumetric concentration at the bottom boundary of the computational domain with respect to the variation of the considered flow controlling parameters, is investigated, at a flow stage that the generated, continuous, highdensity turbidity current flows are still in progress. For this purpose in Figure 13, the suspended sediment volumetric concentration at the bottom boundary of the domain is plotted against the horizontal distance from the inflow gate, for flow time $t=40 \mathrm{sec}$, where the flow of generated turbidity currents have reached a quasi-steady state, while still being in progress. For comparison purposes, the varied parameter in each series of numerical experiments is normalized with its lowest value ( $S_{1}=1$ for Series $\mathrm{A}, C_{5}=5 \%$ by vol. for Series B, $D_{80}=80 \mu \mathrm{m}$ for Series C and $R_{80}=80 \mu m$ for Series D), the horizontal distance $X$ from the inflow gate, is normalized with the width of the inclined channel $(b=0.22 \mathrm{~m})$ and the suspended sediment volume fraction at the bottom boundary $C_{v o l}$ is normalized with the values, $C_{S 1}=0.25$ for Series A, $C_{C 5}=0.05$ for Series B, $C_{D 80}=0.25$ for Series C and $C_{R 80}=0.25$ for Series D numerical experiments. It should be mentioned that the suspended sediment volume fraction values at the bottom boundary of the computational domain, are taken at the central axis of the generated flows. From Figure 13 it is obvious that in all cases the resulting curves have a similar form. In more detail, in the laterally constrained and sloped bottom part of the flow (channel), the suspended sediment volumetric concentration at the bottom boundary increases rapidly with the longitudinal distance from the inflow gate, up to a distance of $\frac{X}{b} \approx 1$ and then follows a less rapid increase up to a maximum value, at a distance of $\frac{X}{b} \approx 11$ that is close to the downstream end 
of the channel $\left(\frac{X}{b} \approx 13.6\right)$. The rapid increase of the volume fraction values in the vicinity of the inflow point ( $\frac{X}{b}=0$ to 1$)$ is probably due to the local increase of the inflowing mixtures volume fraction value, as a result of the resistance that is exerted from the ambient fluid. In the unconstrained and horizontal bottom part of the flow (tank), the suspended sediment volumetric concentration follows an irregular decrease with respect to the longitudinal distance, reaching an almost constant minimum value in the vicinity of the downstream boundary of the computational domain. The fact that in all cases, the maximum value of the suspended sediment volumetric concentration at the bottom is found at the downstream end of the channel, is probably due to the sudden reduction in the velocity of the generated turbidity currents, which is a result of the flow transition from the laterally constrained (channel) to the unconstrained (tank) part of the computational domain. This sudden drop of velocity is reasonable to cause intense particle deposition, just upstream of the channel exit.

Comparing the resulting curves in Figure $13 \mathrm{a}$ it is obvious that in the laterally constrained part of the flow (channel), the increase of the channel slope causes a reduction in the suspended sediment volumetric concentration values. The proposed reduction becomes more appreciable as the horizontal distance from the inflow gate increases. The increase of the channel slope causes a subsequent increase in the travelling velocity of the generated turbidity current (Figure 10a), which results in a reduction of the suspended sediment settling rate. As for the unconstrained part of the flow (tank), excluding the curve that corresponds to numerical experiment S1 ( $S_{i} / S_{S 1}=1$ ), a similar effect of the channel slope increase in the suspended sediment volumetric concentration can be observed, as within the inclined channel. The only difference is that the decrease of the suspended sediment volumetric concentration values is less appreciable as the horizontal distance from the inflow gate increases. The unusual, rapid decrease of the suspended sediment volume fraction values at the bottom boundary of the tank, for the case of numerical experiment $\mathrm{S} 1\left(S_{i} / S_{S 1}=1\right)$, can be probably attributed to the fact that the generated turbidity current in the proposed numerical experiment, spreads out with a much larger expansion angle (Figure 11 a) than in the case of numerical experiments S5, S10 кal S20 ( $\left.S_{i} / S_{S 1}=5,10,20\right)$. Therefore, the reduction rate of the suspended sediment 
volumetric concentration on the central flow axis is larger, due to the larger deposition field at the left and right of the proposed axis.

Comparing the resulting curves of Figure $13 \mathrm{~b}$ it can be concluded that the increase of the initial suspended sediment volumetric concentration causes an almost equivalent increase in the values of the suspended sediment volume fraction at the bottom boundary of the computational domain, both in the laterally constrained (channel) and the unconstrained (tank) parts of the flow. It is characteristic that the resulting curves are almost parallel to each other. In more detail, the increase rate of the suspended sediment volume fraction values at the bottom boundary of the computational domain, with respect to the corresponding increase of the inflow mixture suspended sediment volumetric concentration, is almost the same in any position $(X / b)$ of the main, central flow axis. This is probably due to the fact that the generated turbidity currents in the numerical experiments of Series B, have the same suspended sediment deposition rate, since the grain diameter of the suspended sediment particles, the channel bed slope as well as the bed roughness of the channel and the tank remain constant (Table 2).

Comparing the resulting curves in Figure 13c, it can be concluded that the increase of the suspended sediment grain diameter, causes a subsequent increase in the suspended sediment volume fraction values at the bottom boundary, both in the channel and the tank. It is characteristic that in the inclined channel bottom, the proposed increase becomes progressively more appreciable, as the horizontal distance from the inflow gate increases. The maximum differences at the volume fraction values are traced at the position of maximum deposition $(X / b=11)$. On the contrary, at the bottom of the tank, the differences in the volume fraction values from experiment to experiment, become progressively less appreciable, as the horizontal distance from the downstream end of the inclined channel increases. The general increase of the suspended sediment volume fraction values at the bottom boundary with respect to the increase of the suspended sediment grain diameter, can obviously be attributed to the subsequent increase of the suspended particles settling velocity.

From Figure $13 \mathrm{~d}$ it can be concluded that the increase of the bed roughness, causes a small increase in the suspended sediment volume fraction values, both in the bottom boundary of the inclined channel and the tank. It is characteristic that in the bottom of the inclined channel, the proposed increase becomes progressively more appreciable, as the horizontal distance from the inflow gate increases, with the 
maximum differences to be tracked at the position of the maximum sediment deposition $(X / b=11)$. On the contrary, at the bottom of the tank, the differences in the values of the suspended sediment volume fraction, from experiment to experiment, are almost constant up to a horizontal distance from the inflow gate ( $X / b=20)$. Downstream of this position a progressive increase in the proposed differences is observed, from experiment to experiment. The general increase in the values of the suspended sediment volume fraction at the bottom boundary of the computational domain, in relation to the increase of the bottom boundary roughness, is probably due to the corresponding reduction of the travelling velocity of the generated in each case turbidity current (Figure 10d), which causes a progressive increase in the suspended sediment deposition rate.

From the overall results of the present subsection it can be concluded that the suspended sediment deposition, during active flow stages of turbidity currents, show a direct, strong dependence from the dynamic flow characteristics (turbidity current flow velocity and expansion angle) and is not primarily controlled by the initial suspended sediment composition, as in the case of the long-term deposits (long after the passage of the turbidity currents) that the suspended sediment particles have been fully deposited.

\subsection{Comparison of relative percentage effect of the investigated flow controlling parameters in fundamental flow characteristics}

From the presentation and the analysis of the above results so far, it is evident that the investigated controlling parameters affect with a different way and in a comparably different degree, the dynamic and depositional characteristics of turbidity currents. According to the authors' best knowledge there are not any previous investigations that actually compare the effect of different flow controlling parameters, in fundamental flow characteristics of turbidity currents, evaluating which parameters are the most or less important. Therefore, in order to compare the relative percentage effect of the varied controlling parameters, in the main flow characteristics of the generated turbidity currents, Figure 14 of the present paper, illustrates diagrams of the relative percentage change of the maximum flow front advance velocity (Figure $14 \mathrm{a}$ ), the main expansion angle of the current (Figure $14 \mathrm{~b}$ ) as well as the maximum value of suspended sediment volume fraction at the bottom boundary (Figure $14 \mathrm{c}$ ), in relation to the relative percentage change of all the considered controlling parameters. 
It should be mentioned that for comparison purposes, the relative percentage change in each case is calculated using absolute differences. It should also be mentioned that in the case of Series D numerical experiments, only the experiments R80, R235, and R500 are taken into consideration, where the values of the bottom boundary roughness are greater than zero. From Figure 14, it is obvious that the variation of the initial suspended sediment concentration as well as the suspended sediment grain diameter have the biggest effect in the flow of the generated turbidity currents. This can be probably attributed to the direct effect of the proposed controlling parameters in the main driving force of turbidity currents, which is the excess density of the current in relation to the ambient water density. The variation of the bed roughness has the smallest effect, while the variation of the channel slope causes a moderate effect in the turbidity current flows, in relation to the rest controlling parameters.

\section{Conclusions}

In the present paper, the three-dimensional, multiphase numerical approach for the numerical simulation of turbidity current flows that is validated in the work of Georgoulas et al. (2010) [1], is further applied in order to investigate the exact qualitative and quantitative effect of fundamental flow controlling parameters, such as bed slope and roughness, initial suspended sediment concentration and diameter, in the hydrodynamic and depositional characteristics of continuous, high density turbidity currents. Apart from widely studied in previous investigations hydrodynamic characteristics, such as the flow front advance with respect to time, it is the first time that the responses of the expansion angle as well as the suspended sediment depositions of continuous, non-depletive, high-density turbidity currents are evaluated, at a stage that the passage of the sustained flow from the considered domain has reached a quasi-steady state, while still being in progress. Moreover, the present investigation constitutes the first attempt in the literature, where the isolated effects of each individual controlling parameter as well as their relative importance on the hydrodynamic characteristics of continuous, high-density turbidity currents are quantitatively evaluated in detail.

The main conclusions of the present numerical investigation that are summarized below can be directly related to field scale, natural hyperpycnal turbidity currents that are usually formed at river outflows (inflow gate) and initially travel 
within a subaqueous canyon (inclined channel) and then, after they exit the downstream end of the canyon, they spread out unconfined in the horizontal or mild sloped bottom of the receiving basin (expansion tank), where they gradually lose their strength and deposit the initially suspended sediment particles:

- Each one of the examined flow controlling parameters affects differently the main flow characteristics of turbidity currents, such as the flow front advance with respect to time, the main expansion angle in the unconfined part of the flow and the deposit density distribution at the bottom boundary.

- In all cases, the flow front advance of the generated turbidity currents consists of three different stages. An initial stage, where the flow front velocity is steady (from the inflow point up to the middle of the inclined channel, approximately), an intermediate stage where a gradual acceleration of the front is observed (from the middle of the inclined channel up to the entrance of the current to the expansion tank) and a final stage where a gradual deceleration of the front is observed (from the entrance of the current to the expansion tank up to its exit from the downstream open boundary).

- The main expansion angle of the generated turbidity currents at the expansion tank, when their flow has reached a quasi-steady state, is found to decrease exponentially with the increase of the densimetric Froude number, at the downstream boundary of the inclined channel.

- In all of the examined cases, when the flow of the generated turbidity currents has reached a quasi-steady state, the maximum value of the deposit density at the bottom boundary is located at a horizontal distance from the inflow point, approximately equal to eleven times the channel width, which, for the geometric configuration considered in the present paper, is located just upstream of the channel downstream end.

- Examining separately the effect of each controlling parameter, in the flow front advance velocity, in the main expansion angle of the current at the unconstrained part of the flow and in the deposit density of the current at the bottom boundary, it can be concluded that in general, the increase of the channel slope causes an increase in the flow front advance velocity and a reduction in the main expansion angle as well as in the deposit density. The increase of the initial suspended sediment concentration causes an increase in 
the flow front advance velocity, in the main expansion angle and in the deposit density. The increase of the suspended sediment grain diameter causes an increase in the flow front advance velocity as well as in the deposit density and a reduction in the main expansion angle of the current. Finally, the increase of the bed roughness causes a reduction in the flow front advance velocity and an increase in the main expansion angle as well as in the deposit density.

- From the comparison of the relative percentage effect of all the examined controlling parameters in the maximum flow front advance velocity, in the main expansion angle of the current and in the maximum value of the deposit density, it can be concluded that the greater effect in each case is caused from the variation of the initial suspended sediment concentration as well as from the variation of the suspended sediment grain diameter. The variation of the bed roughness has in each case a minor effect, while the variation of the channel bed slope has an intermediate effect.

The overall results of the present numerical investigation contribute considerably in the understanding of the dependence of the suspended sediment transport and deposition mechanism, from fundamental flow controlling parameters of natural, continuous, high-density turbidity currents that are usually formed during flood discharges at river outflows. Furthermore, the present numerical investigation indicates the capabilities of an uncommon, numerical approach, as a possible and suitable tool for the further investigation of the hydrodynamic behavior of turbidity currents and particle-laden flows in general, allowing the identification and the continuous monitoring of a wide range of flow parameters, with a relatively high accuracy. The main advantage of the present multiphase numerical approach in relation to previous numerical investigations on turbidity currents (that use a quasisingle phase approach where a single velocity field is calculated for the ambient fluid, while the suspended sediment transport is treated through an advection-diffusion equation for sediment concentration), is that a separate velocity field is calculated for each phase (water and sediment classes), since the laws for the conservation of mass and momentum are modified accordingly in order to be satisfied by each phase individually.

For further investigation, the content of the present paper can be extended, conducting similar parametric numerical experiments in field scale turbidity currents, 
examining more flow controlling parameters and widening the value variation range of each examined parameter.

\section{Acknowledgements}

The authors would like to thank Dr. Charlotte Gladstone and Dr. Jaco H. Baas for making their experimental data available for comparison purposes, as well as the reviewers for the useful comments and recommendations on the initially submitted manuscript. The authors would also like to acknowledge the financial support from the Beachmed-e European Research Project.

\section{References}

1. Georgoulas A, Angelidis P, Panagiotidis T, Kotsovinos N (2010) 3D numerical modelling of turbidity currents. Journal of Environmental Fluid Mechanics 10: 603-635

2. Mulder T, Alexander J (2001) The physical character of subaqueous sedimentary density flows and their deposits. Sedimentology 48: 269-299

3. Janbu NE, Nemec W, Kırman E, Özaksoy V (2009) Facies anatomy of a channelized sandrich turbiditic system: the Eocene Kusuri Formation in the Sinop Basin, north-central Turkey. In: Nichols G, Paola C, Williams E, Paola C (eds) Sedimentary processes, environments and basins. Wiley, Special Publication Number 38 of the International Association of Sedimentologists, Kingston upon Thames, UK, p. 457-517

4. Posamentier HW, Kolla V (2003) Seismic geomorphology and stratigraphy of depositional elements in deep-water settings. Journal of Sedimentary Research 73 (3): 367-388

5. Lovell JPB (1971) Control of slope on deposition from small-scale turbidity currents: experimental results and possible geological significance. Sedimentology 17: 81-88

6. Simpson JE, Britter RE (1979) The dynamics of the head of a gravity current advancing over a horizontal surface. Journal of Fluid Mechanics 94: 477-495

7. Britter RE, Linden PF (1980) The motion of the front of a gravity current travelling down an incline. Journal of fluid mechanics 99: 531-543

8. Garcia M, Parker G (1989) Experiments on hydraulic jumps in turbidity currents near a canyon-fan transition. Science (doi:10.1126/science.245.4916.393)

9. Garcia M (1994) Depositional turbidity currents laden with poorly sorted sediment. Journal of Hydraulic Engineering 120 (11): 1240-1263

10. Kneller BC, Bennett SJ, McCaffrey WD (1997) Velocity and turbulence structure of density currents and internal solitary waves: potential sediment transport and the formation of wave ripples in deep water. Sedimentary Geology 112: 235-250

11. Gladstone C, Phillips JC, Sparks RSJ (1998) Experiments on bidisperse, constant-volume gravity currents: propagation and sediment deposition. Sedimentology 45: 833-843

12. Baas JH, Van Kesteren W and Postma G (2004) Deposits of depletive, quasi-steady high density turbidity currents: a flume analogue of bed geometry, structure and texture. Sedimentology 51: 1053-1089

13. Felix M, Peakall J (2006) Transformation of debris flows into turbidity currents: mechanisms inferred from laboratory experiments mechanisms inferred from laboratory experiments. Sedimentology 53: 107-123 
14. Bonnecaze RT, Hallworth MA, Huppert HE, Lister JR (1995) Axisymmetric particle-driven gravity currents. Journal of Fluid Mechanics 294: 93-121.

15. Wen F, Evans J (1996) Effect of particle inertia on the instability of a particle-laden flow. Computer and Fluids 25 (7): 667-676

16. Hartel C, Meiburg E, Necker F (2000) Analysis and direct numerical simulation of the flow at a gravity-current head: Part 1. Flow topology and front speed for slip and no-slip boundaries. Journal of Fluid Mechanics (418): 189-212

17. Kassem A, Imran J (2001) Simulation of turbid underflows generated by the plunging of a river. Geology 29 (7): 655-658

18. Heimsund S, Hansen EWM, Nemec W (2002) Computational 3D fluid-dynamics model for sediment transport, erosion and deposition by turbidity currents. In: KnoperM, Cairncross B (eds), Abstracts, international association of sedimentologists 16th international sedimentological congress, Rand Afrikaans University, Johannesburg, p. 151-152

19. Lavelli A, Boillat JL, De Cesare G (2002) Numerical 3D modelling of the vertical mass exchange induced by turbidity currents in Lake Lugano (Switzerland). In: Proceedings 5th international conference on hydroscience and engineering (ICHE-2002) (Reference: LCH-CONF2002-012 Note: [355])

20. Necker F, Hartel C, Kleiser L, Meinburg E (2002) High-resolution simulations of particle driven gravity currents. International journal of multiphase flow 28: 279-300

21. Cantero M, Garcia M, Buscaglia G, Bombardelli F, Dari E (2003) Multidimensional CFD simulation of a discontinuous density current. In: Proceedings of the XXX IAHR international congress, Thessaloniki, Greece.

22. Bombardelli FA, Cantero MI, Buscaglia GC, García MH (2004) Comparative study of convergence of CFD comercial codes when simulating dense underflows. In: Buscaglia G, Dari E, Zamonsky O (eds), Mec'anica Computacional, vol XXIII. Bariloche, Argentina

23. Imran J, Kassem A, Khan SM (2004) Three-dimensional modeling of density current. I. Flow in straight confined and unconfined channels. Journal of Hydraulic Research 42 (6): 578-590

24. Blanchette F, Strauss M, Meiburg E, Kneller B, Glinsky ME (2005) High-resolution numerical simulations of resuspending gravity currents: conditions for self-sustainment. Journal of Geophysical Research, 110, C12022, (doi:10.1029/2005JC002927)

25. Huang H, Imran J, Pirmez C (2005) Numerical model of turbidity currents with a deforming bottom boundary. Journal of Hydraulic Engineering 131 (4): 283-293

26. Blanchette F, Piche V, Meiburg E, Strauss M (2006) Evaluation of a simplified approach for simulating gravity currents over slopes of varying angles. Computers and Fluids 35: 492-500

27. Cantero MI, Balachandar S, Garcia MH (2007) High-resolution simulations of cylindrical density currents. Journal of Fluid Mechanics 590: 437-469

28. Ünes F (2008) Investigation of density flow in dam reservoirs using a three-dimensional mathematical model including Coriolis effect. Computers \& Fluids 37: 1170-1192

29. Mehdizadeh A, Firoozabadi B, Farhanieh B (2008) Numerical simulation of turbidity current using $\mathrm{v}^{2}-\mathrm{f}$ turbulence model. Journal of Applied Fluid Mechanics 1 (2): 45-55

30. Cantero MI, Balachandar S, Garcia MH (2008a) An Eulerian-Eulerian model for gravity currents driven by inertial paricles. International Journal of Multiphase Flow 34: 484-501

31. Cantero MI, Balachandar S, Garcia MH, Bock D (2008b) Turbulent structures in planar gravity currents and their influence on the flow dynamics. Journal of Geophysical Research, 113, C08018, (doi:10.1029/2007JC004645)

32. Singh J (2008) Simulation of suspension gravity currents with different initial aspect ratio and layout of turbidity fence. Applied Mathematical Modelling 32: 2329-2346

33. Nasr-Azadani MM, Meiburg E (2010) TURBINS: An immersed boundary, Navier-Stokes code for the simulation of gravity and turbidity currents interacting with complex topographies. Computers and fluids, Article in press, (doi:10.1016/j.compfluid.2010.11.023)

34. ANSYS FLUENT Documentation (2012) www.ansys.com

35. Monaghan JJ, Cas RAF, Kos AM, Hallworth M (1999) Gravity currents descending a ramp in a stratified tank. Journal of Fluid Mechanics 379: 39-69 
36. Özgökmen TM, Chassignet EP (2002) Dynamics of two-dimensional turbulent bottom gravity currents. Journal of Physical Oceanography 32 (5): 1460-1478.

\section{Figure Captions}

Figure 1 Comparison of numerical [1] and experimental [11] results, of flow front advance with respect to time.

Figure 2 Comparison of numerical dimensionless velocity profiles [1] with analogous experimental data [9], for numerical Runs A, and D that reproduce the experiments of Gladstone et al. (1998) [11].

Figure 3 Variation of head velocity with respect to the initial suspended sediment concentration for turbidity currents laden with fine sand, very fine sand and coarse silt. Comparison of numerical [1] and experimental results [12].

Figure 4 Comparison of numerical dimensionless velocity profiles [1] with analogous experimental data [9], for numerical Runs 1, 7 and 14 that reproduce the experiments of Baas et al. (2004) [12].

Figure 5 General configuration of investigated physical problem.

Figure 6 Computational geometry, computational mesh and boundary conditions of numerical simulations (R.N.E.).

Figure 7 Sensitivity test of mesh size on the position of the turbidity current front with respect to time.

Figure 8 Three-dimensional time evolution of the interface (grey surface) between the generated turbidity current and the ambient water (R.N.E.).

Figure 9 Time evolution of density contours within the generated turbidity current, in a vertical $\mathrm{ZX}$ section plane, in the middle of the computational domain $(\mathrm{Y}=0 \mathrm{~m})$. The density values are determined by the color scale of the legend (R.N.E.).

Figure 10 Dimensionless flow front position with respect to dimensionless time for, (a) Series A, (b) Series B, (c) Series C and (d) Series D, numerical experiments.

Figure 11 Variation of turbidity current's expansion angle $(\varphi)$ and of densimetric Froude number at the downstream end of the channel $\left(\mathrm{Fr}_{\mathrm{d}}\right)$, in relation to the varied controlling parameter $40 \mathrm{sec}$ after the entrance of the fresh water - suspended sediment mixtures, for (a) Series A, (b) Series B, (c) Series C and (d) Series D, numerical experiments.

Figure 12 Dependence of expansion angle of the generated turbidity currents within the tank, from the densimetric Froude number, at the exit point of the inclined channel (Series A, B, C and D numerical experiments), at flow time $\mathrm{t}=40 \mathrm{sec}$, were the flow of the generated turbidity currents has reached a quasi-steady state.

Figure 13 Dimensionless suspended sediment volume fraction at the bottom boundary of the computational domain, with respect to the dimensionless horizontal distance from the inflow gate for, (a) Series 
A, (b) Series B, (c) Series C and (d) Series D, numerical experiments, $40 \mathrm{sec}$ after the beginning of the inflow of the fresh water - suspended sediment mixtures.

Figure 14 Dependence of the maximum flow front velocity (a), the expansion angle (b) and the maximum suspended sediment volume fraction at the bottom boundary of the computational domain (c), from the investigated flow controlling parameters (expressed as relative percentage changes).

\section{Table Captions}

Table 1 Numerical model set-up parameters and characteristics in ANSYS FLUENT.

Table 2 Investigated, fundamental controlling parameters, of turbidity current flows.

Table $3 \quad$ Numerical experiments initial conditions.

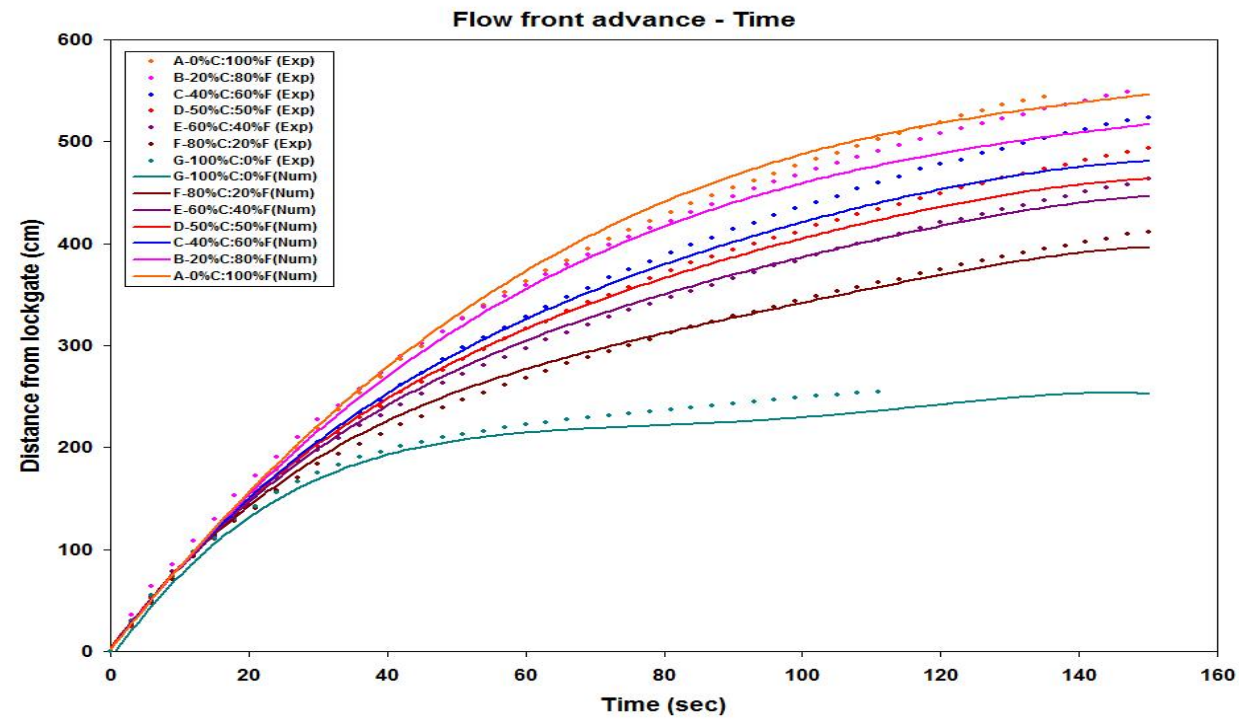

Fig. 1

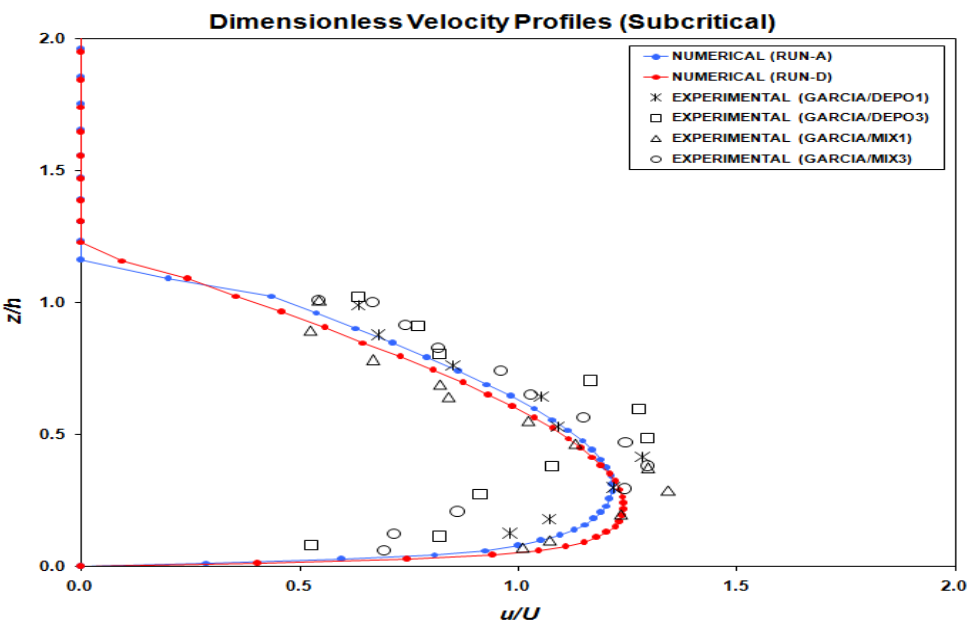

Fig. 2 
Head Velocity - Sediment Concentration

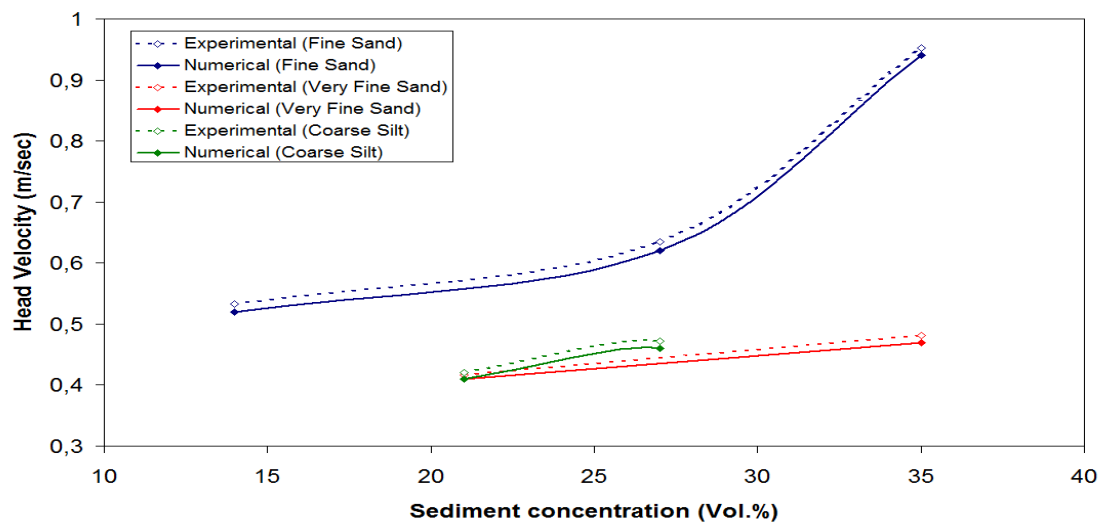

Fig. 3

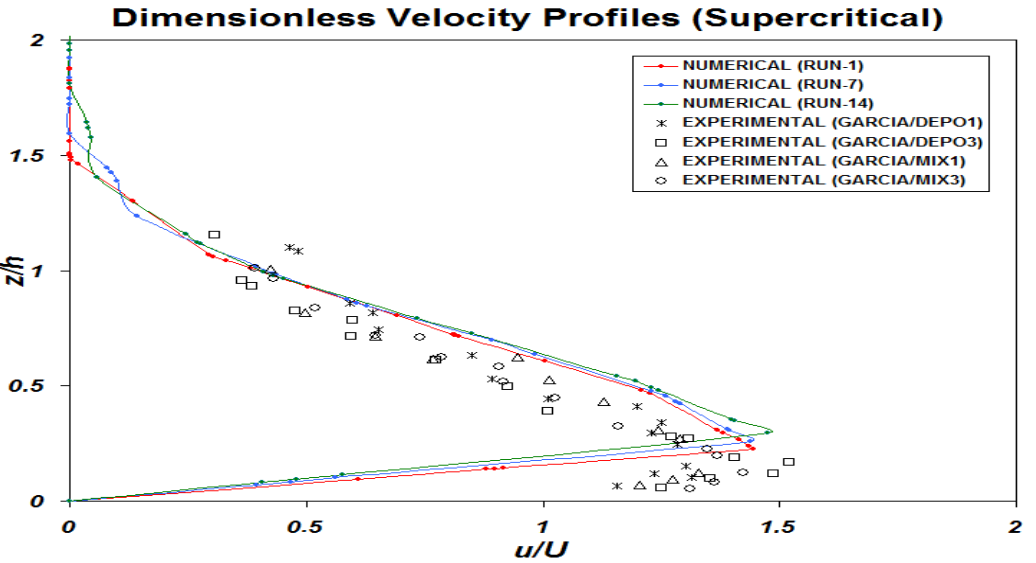

Fig. 4
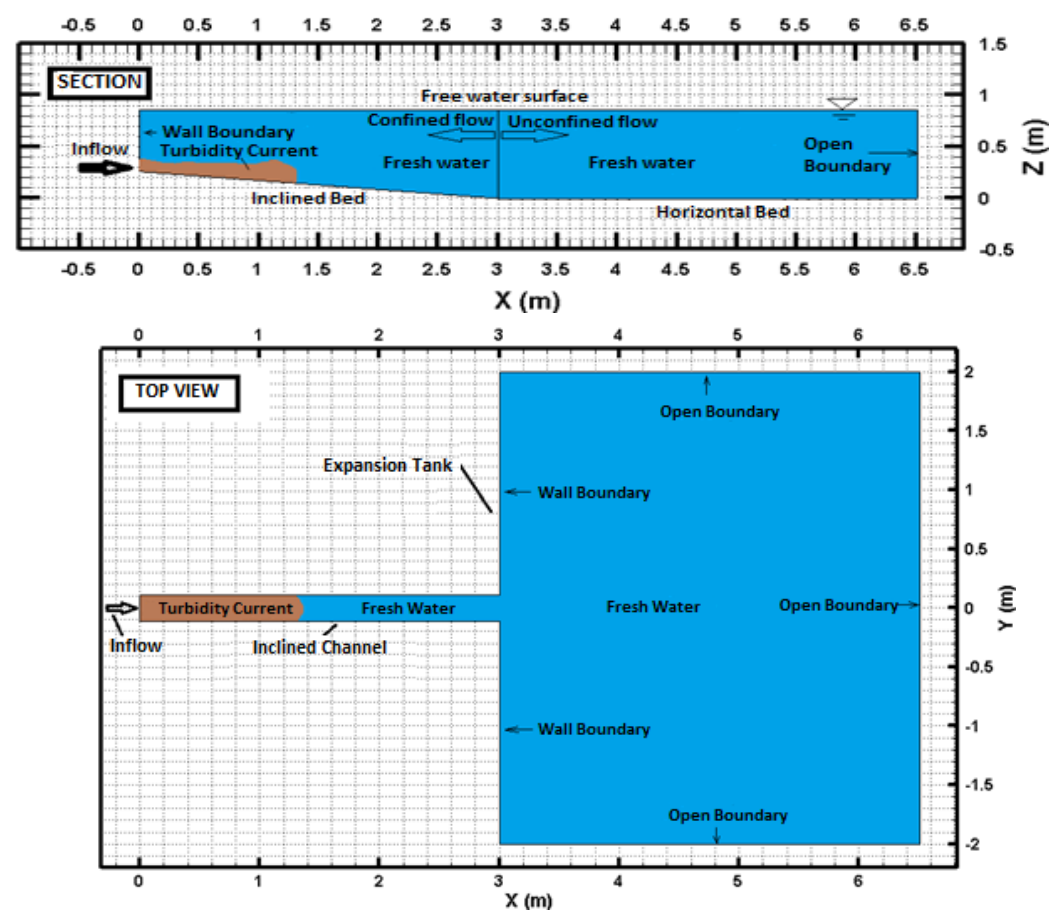

Fig. 5 


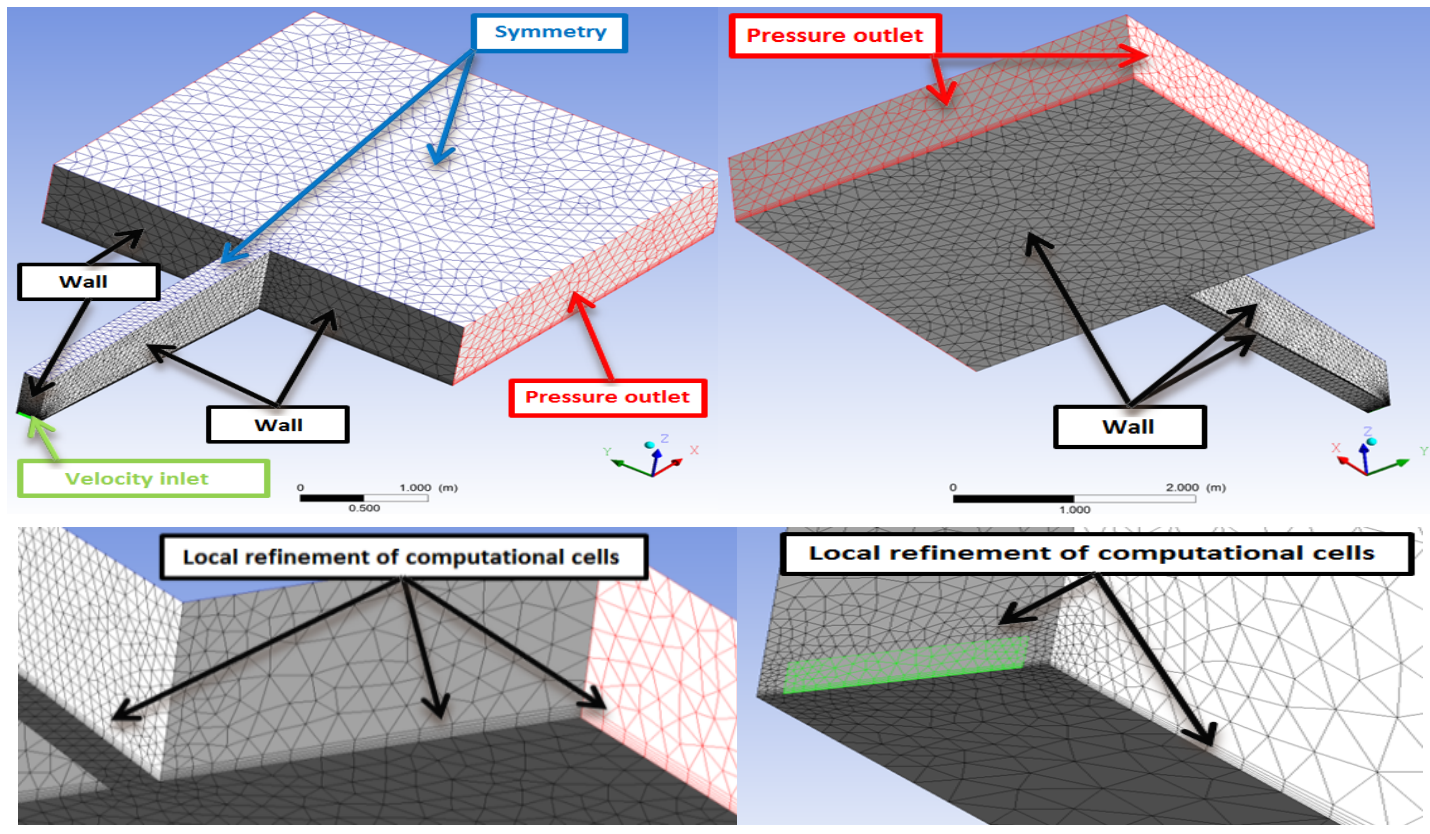

Fig. 6

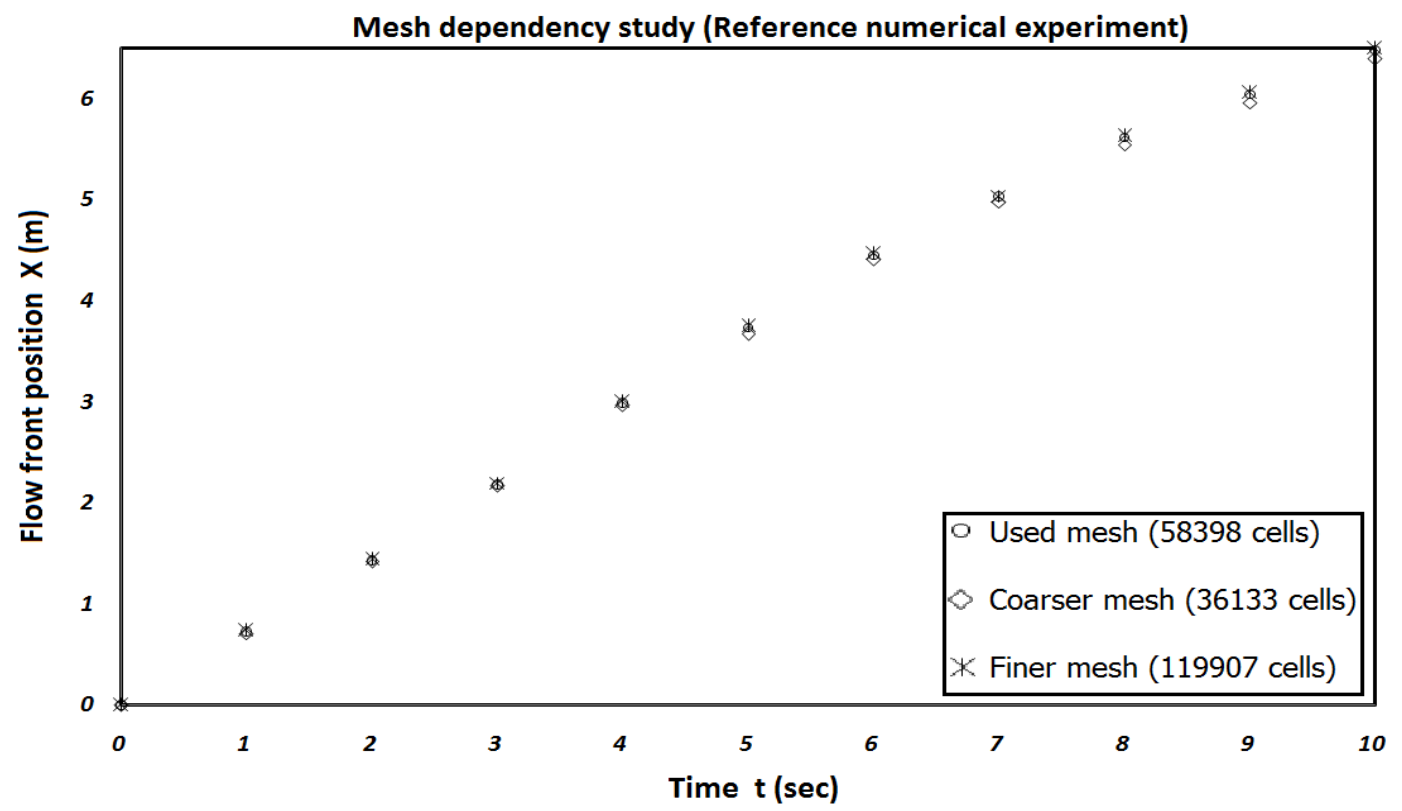

Fig. 7 

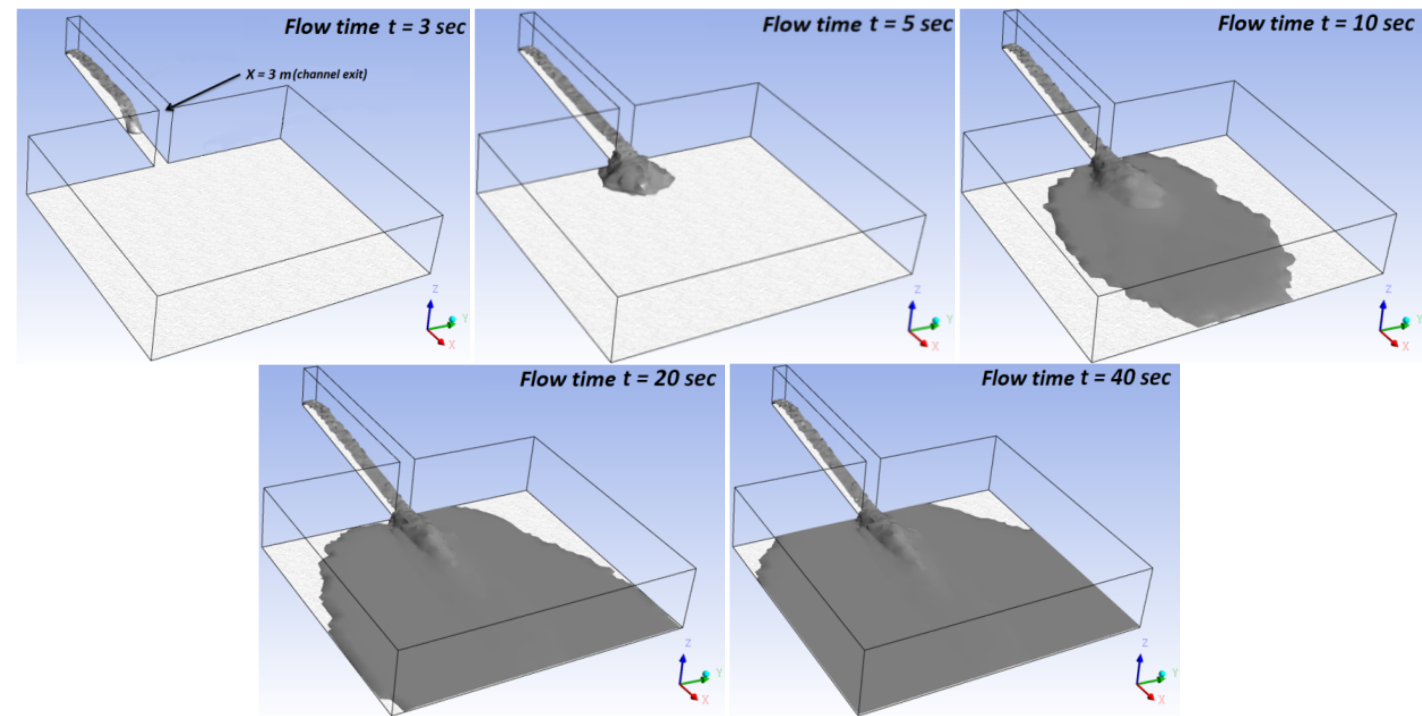

Mixture density $\left(\mathrm{kgr} / \mathrm{m}^{3}\right)$
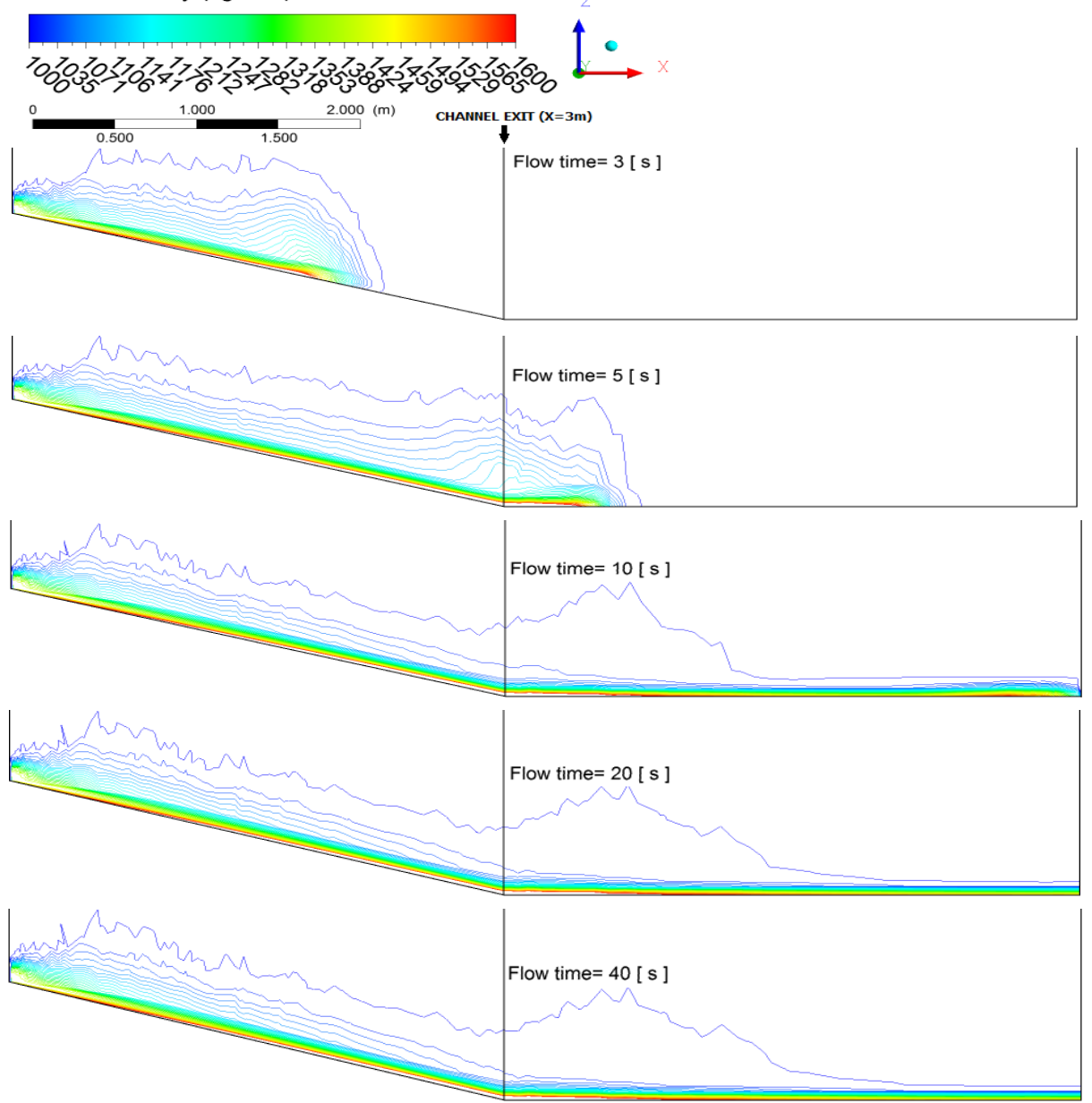

Fig. 9 

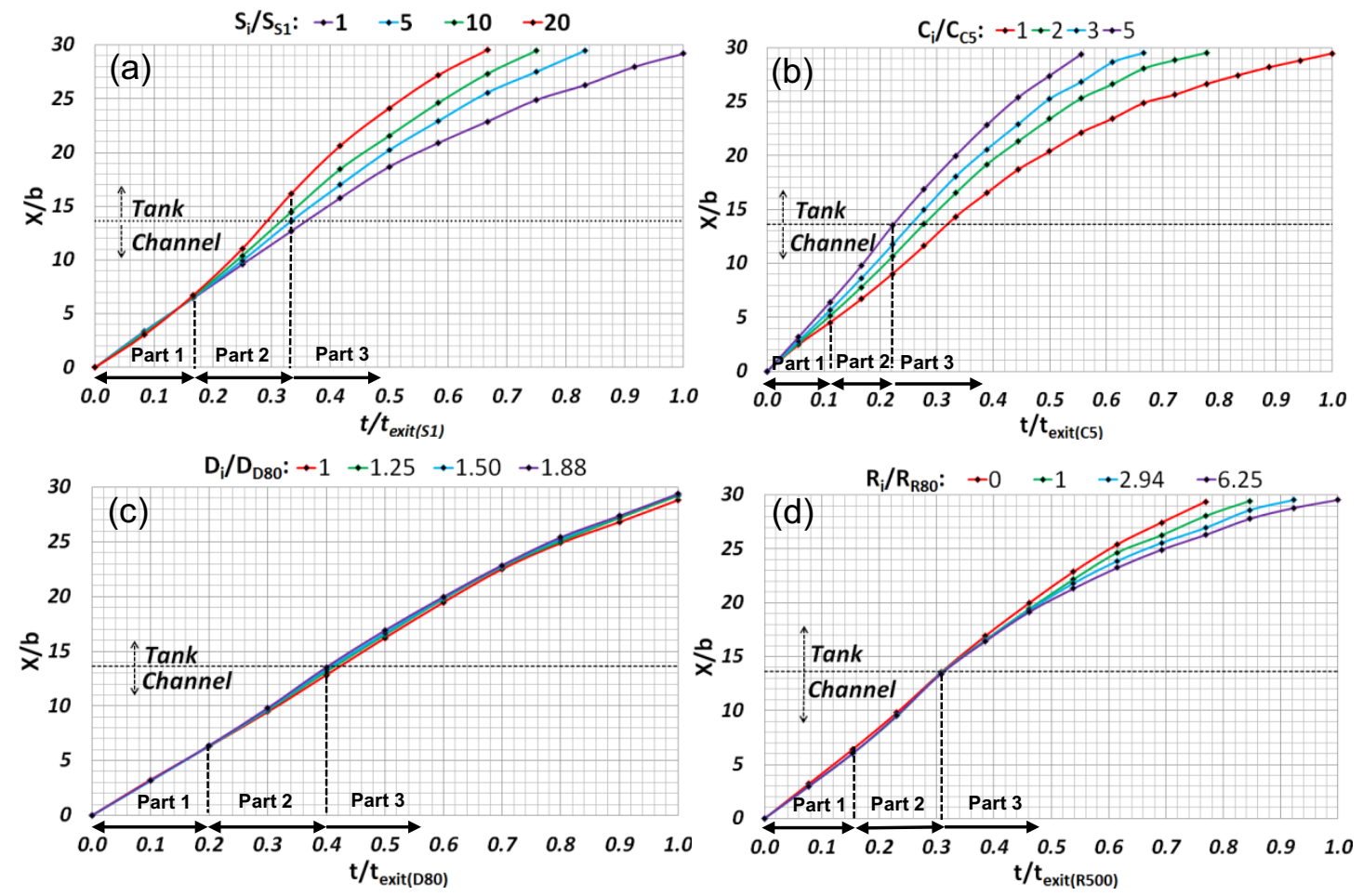

Fig. 10
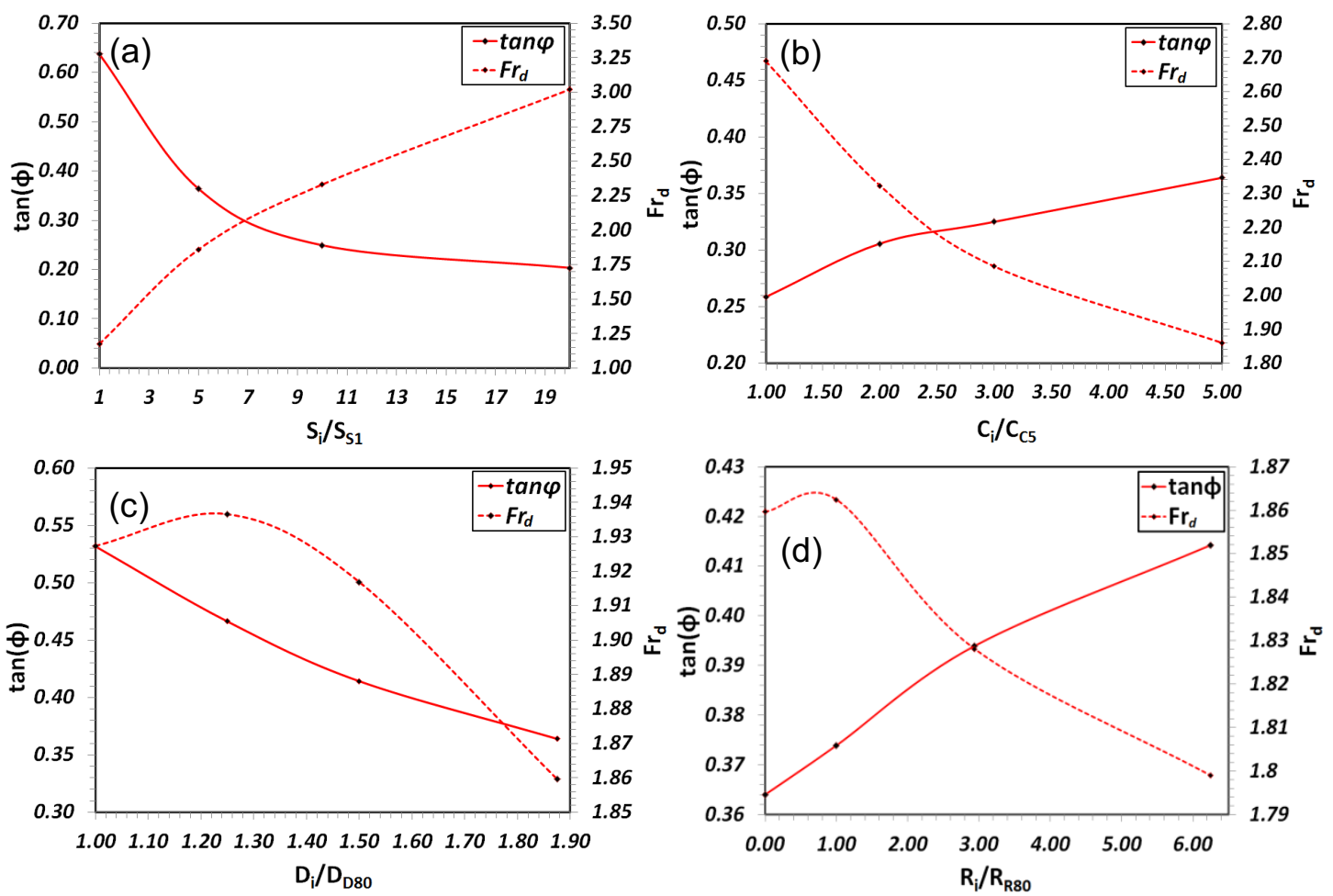

Fig. 11 


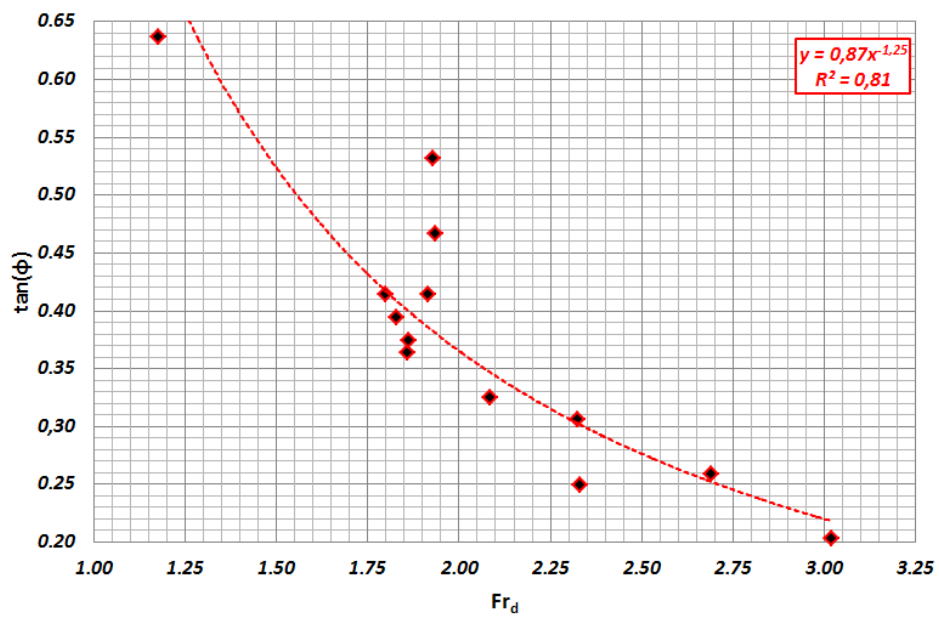

Fig. 12
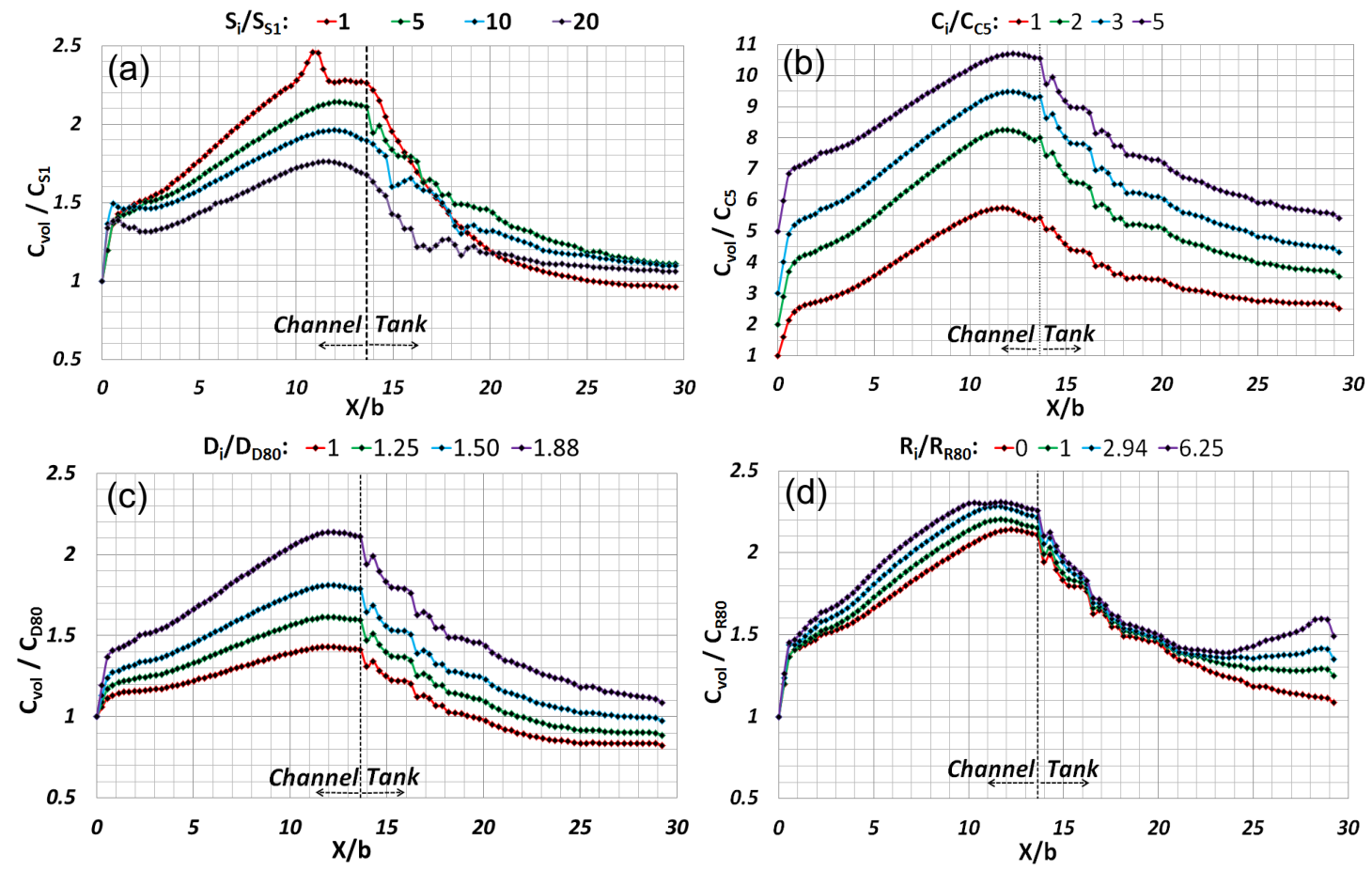

Fig. 13 

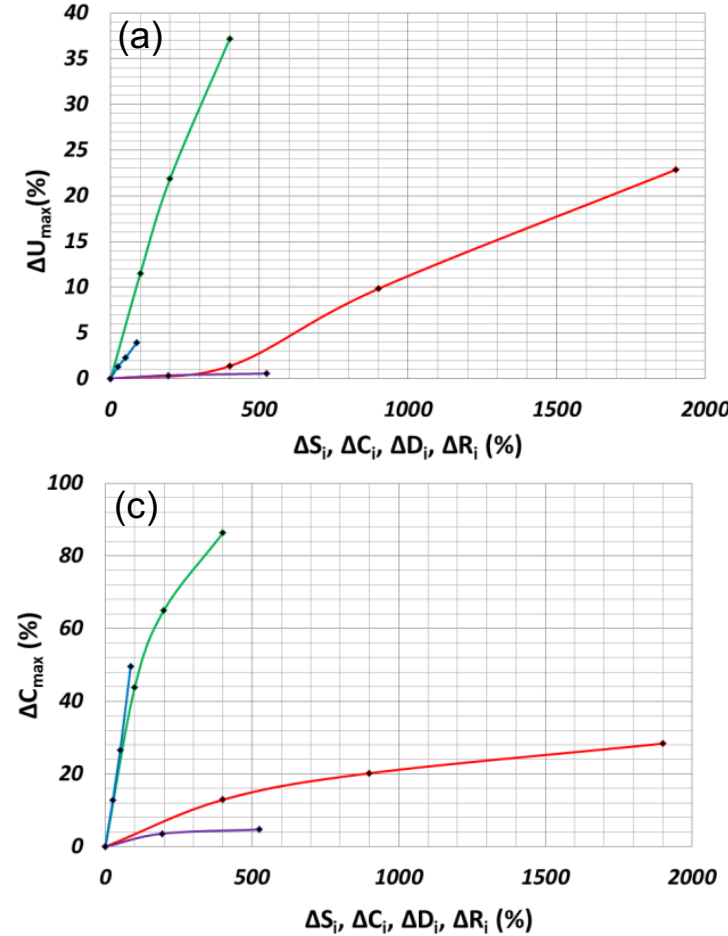

Fig. 14
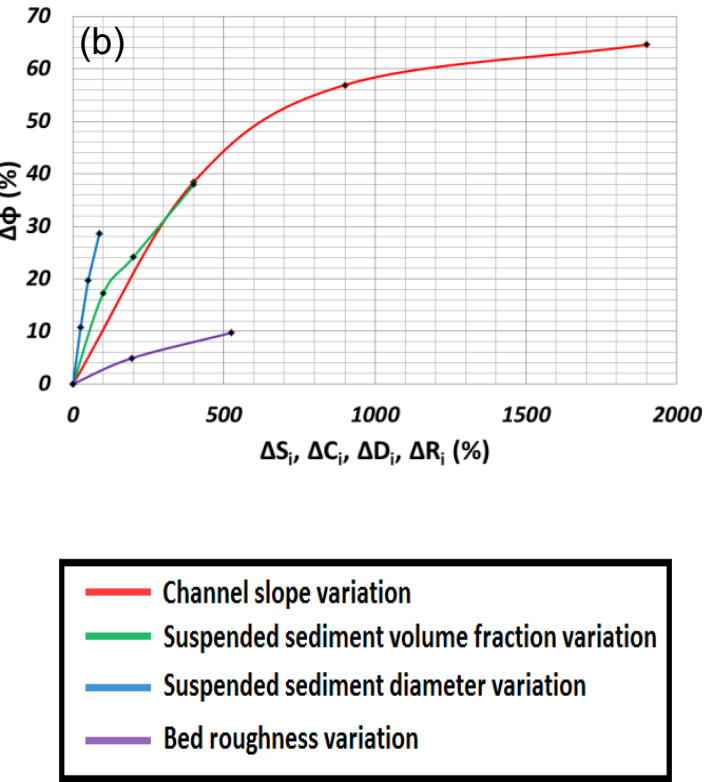
Table 1

A. MODEL SET-UP

\begin{tabular}{|c|c|}
\hline \multicolumn{2}{|l|}{ A1. SOLVER } \\
\hline Type & Pressure based \\
\hline Velocity formulation & Absolute \\
\hline Space & $3 D$ \\
\hline Time & Transient/Unsteady \\
\hline \multicolumn{2}{|c|}{ A2. MULTIPHASE MODEL } \\
\hline Name & Eulerian \\
\hline Scheme & Implicit \\
\hline No. of phases & 2 \\
\hline \multicolumn{2}{|c|}{ A3. TURBULENCE MODEL } \\
\hline Name & RNG k- $\varepsilon$ \\
\hline Used options & Differential Viscosity Model, Swirl Dominated Flow \\
\hline Near-wall treatment & Enhanced Wall Treatment \\
\hline Multiphase modification & Dispersed \\
\hline \multicolumn{2}{|l|}{ A4. PHASES } \\
\hline Primary & Fresh water \\
\hline Secondary & Suspended sediment particles \\
\hline
\end{tabular}

\section{B1. Methods}

Pressure-velocity coupling scheme

Spatial discretization schemes

\begin{tabular}{|l|l|}
\hline Gradient & Green-Gauss Cell Based \\
\hline Momentum & Second Order Upwind \\
\hline Volume fraction & QUICK \\
\hline Turbulent kinetic energy & Second Order Upwind \\
\hline Turbulent dissipation rate & Second Order Upwind \\
\hline Time discretization scheme & Second Order Implicit \\
\hline Transient formulation & \multicolumn{2}{|l|}{} \\
\hline B2. Controls & 0.3 \\
\hline Under-relaxation factors & 0.7 \\
\hline Pressure & 0.2 \\
\hline Momentum & 0.8 \\
\hline Volume fraction & 0.8 \\
\hline Turbulent kinetic energy & Absolute \\
\hline Turbulent dissipation rate & 0.001 \\
\hline Convergence & \multicolumn{2}{|l}{} \\
\hline Type & Fixed \\
\hline Criterion & 0.1 \\
\hline B3. Calculation & 1000 \\
\hline Time stepping method & \\
\hline Time step size (sec) & \\
\hline Total number of time steps & \\
\hline
\end{tabular}


Table 2

\begin{tabular}{|c|c|c|c|}
\hline $\begin{array}{c}\text { Numerical } \\
\text { Experiments } \\
\text { Series }\end{array}$ & $\begin{array}{c}\text { Investigated/Varied } \\
\text { Parameter }\end{array}$ & Symbol & Explanation \\
\hline A & Channel slope & $\mathbf{S}_{\mathbf{i}}$ & "inclination angle of channel bed" \\
\hline B & $\begin{array}{c}\text { Suspended sediment } \\
\text { concentration }\end{array}$ & $\mathbf{C}_{\mathbf{i}}$ & $\begin{array}{c}\text { "Initial, volumetric concentration of } \\
\text { suspended sediment particles in the } \\
\text { inflow mixture" }\end{array}$ \\
\hline C & Grain diameter & $\mathbf{D}_{\mathbf{i}}$ & $\begin{array}{c}\text { "Grain diameter of suspended sediment } \\
\text { particles in the inflow mixture" }\end{array}$ \\
\hline D & Bed roughness & $\mathbf{R}_{\mathbf{i}}$ & $\begin{array}{c}\text { "Roughness of channel and tank bed } \\
\text { expressed as equivalent roughness of } \\
\text { uniformly distributed suspended } \\
\text { sediment particles of specific grain size" }\end{array}$ \\
\hline
\end{tabular}

Table 3

\begin{tabular}{|c|c|c|c|c|c|}
\hline $\begin{array}{l}\text { Numerical } \\
\text { Experiments } \\
\text { Series }\end{array}$ & $\begin{array}{c}\text { Numerical } \\
\text { Experiment } \\
\text { Name }\end{array}$ & $S_{i}\left({ }^{\circ}\right)$ & $\mathrm{C}_{\mathrm{i}}(\% \mathrm{vol})$. & $D_{i}(\mu m)$ & $\mathbf{R}_{\mathbf{i}}(\boldsymbol{\mu m})$ \\
\hline$A$ & $\mathrm{S1}$ & 1 & 25 & 150 & 0 \\
\hline$A$ & S5 (R.N.E) & 5 & 25 & 150 & 0 \\
\hline A & S10 & 10 & 25 & 150 & 0 \\
\hline $\mathrm{A}$ & $\mathrm{S} 20$ & 20 & 25 & 150 & 0 \\
\hline $\mathrm{B}$ & $\mathrm{C} 5$ & 5 & 5 & 150 & 0 \\
\hline B & C10 & 5 & 10 & 150 & 0 \\
\hline $\mathrm{B}$ & C15 & 5 & 15 & 150 & 0 \\
\hline $\mathrm{B}$ & C25 (R.N.E) & 5 & 25 & 150 & 0 \\
\hline $\mathrm{C}$ & D80 & 5 & 25 & 80 & 0 \\
\hline C & D100 & 5 & 25 & 100 & 0 \\
\hline $\mathrm{C}$ & $\mathrm{D} 120$ & 5 & 25 & 120 & 0 \\
\hline $\mathrm{C}$ & D150 (R.N.E) & 5 & 25 & 150 & 0 \\
\hline $\mathrm{D}$ & R0 (R.N.E) & 5 & 25 & 150 & 0 \\
\hline $\mathrm{D}$ & $\mathrm{R} 80$ & 5 & 25 & 150 & 80 \\
\hline $\mathrm{D}$ & R235 & 5 & 25 & 150 & 235 \\
\hline$D$ & R500 & 5 & 25 & 150 & 500 \\
\hline
\end{tabular}

